\title{
Design Parameters Optimization Simulation of a Prototype Segmented Rubber Track Vehicle for Sepang Peat in Malaysia
}

\author{
Ataur Rahman, Azmi Yahya, Mohd. Zohadie, Wan Ishak and Desa Ahmad \\ Faculty of Engineering, Universiti Putra Malaysia, 43400, Serdang, Selangor D.E, Malaysia
}

\begin{abstract}
This study describes a simulation model for studying the basic design parameters of a special rubber track vehicle with rigid link tracks system on Sepang peat terrain in Malaysia. The prototype parameters for a track system, including proper track width, ground contact length, pitch and grouser height, idler diameter and location, sprocket diameter and location, road-wheel diameter and geometrical arrangement, the ratio of the road-wheel spacing to track pitch and location of the center of gravity to ensure good tractive performance. The vehicle track width significantly affects the vehicle external motion resistance. The road-wheel spacing ensures the number of road-wheels and significantly affects the vehicle external motion resistance. The vehicle traveling speed affects the vehicle engine power requirement and vehicle steerability during turning on peat terrain. The simulated performance results such as vehicle average motion resistance coefficient of 6.8 to $7.9 \%$, drawbar pull coefficient of 25.22 to $47 \%$ and the tractive efficiency of 74 to $77 \%$ for the vehicle slippage of 5 to $20 \%$ and indicate that the vehicle can meet the peat terrain field requirement with its optimal power consumption.
\end{abstract}

Key words: Tracked Vehicle, Peat Terrain, Design Parameters, Tractive Performance

\section{INTRODUCTION}

Study and selection the basic design parameters are the major concern for designing a special rubber track vehicle with rigid links track system on peat terrain, Sepang, Malaysia. All major design parameters of the vehicle and track system, including vehicle weight, track width, ground contact length, grouser height and pitch, idler diameter and location, sprocket diameter and location, number of road-wheel, road-wheel diameter and arrangement, location of the center of gravity are taken into account. Terrain characteristics, including the terrain moisture content, bulk density (dry basis), pressure-sinkage relationship, shearing characteristics and response of the terrain to repetitive normal and shear loadings, are taken into account. This study represents the simulation model for a Sepang peat prototype segmented rubber track vehicle. The aim of this model to evaluate the effects of vehicles design parameters on the motion resistance, tractive effort, drawbar pull, engine power requirement and tractive efficiency of the vehicle as functions of track slip on peat terrain.

Background of the Site: Field tests were carried out at Sepang peat area, located about $45 \mathrm{~km}$ from Kuala Lumpur Malaysia. The area was heavily infested with palm roots, low shrubs, grasses and sedges. The field conditions were wet and the water table was found to be 0 to $120 \mathrm{~mm}$ below the surface level. The surface mat and the peat deposit thickness were not distinct by visual observation. The surface mat thickness was about 50 to $250 \mathrm{~mm}$ at the center location between adjacent palm rows and 100 to $350 \mathrm{~mm}$ at the palm tree location. The underlying peat deposit thickness for the whole area was about 500 to $1000 \mathrm{~mm}$. The water field capacity was almost at saturation level and walking on such a terrain condition was only possible with the use of a special made wooden clog. The dominant features of this site may be described as high water content and weak underlying peat that could easily be disturbed by vehicle movements.

The overall area was divided into 3 equal area blocks and each block was again divided into 3 equal subblocks. Each of the sub-blocks was considered as the traveling path of the vehicle. Peat moisture content, bulk density, cohesiveness, internal friction angle, shear deformation modulus, vane shearing strength, surface mat stiffness and underlying stiffness of peat were determined. The Sepang peat terrain parameters are shown in Table 1.

Mathematical Formulation: Considering a rigid link segmented rubber track vehicle of weight $\mathrm{W}$, track size including track ground contact length $\mathrm{L}$, width $\mathrm{B}$, pitch $T_{p}$ and grouser height $H$, radius of the front idler $R_{f i}$, rear sprocket $R_{r s}$ and road-wheel $R_{w}$ and height of center of gravity (C.G) $h_{c g}$, is traversing under traction on a peat terrain at a constant speed of $v_{t}$ by the hydraulic motor driving torque $\mathrm{Q}$ at the rear sprocket by the hydraulic motor (Fig. 1). If the pressure distribution in the track-terrain interface is assumed to be nonuniform 


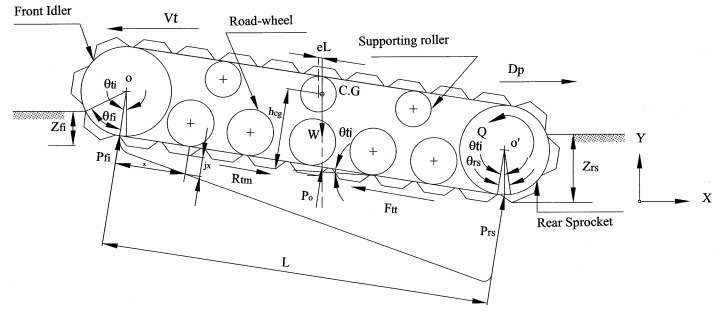

Fig. 1: Force Acting on the Track System of the Vehicle during Traversing on Peat Terrain with Slippage 10\%

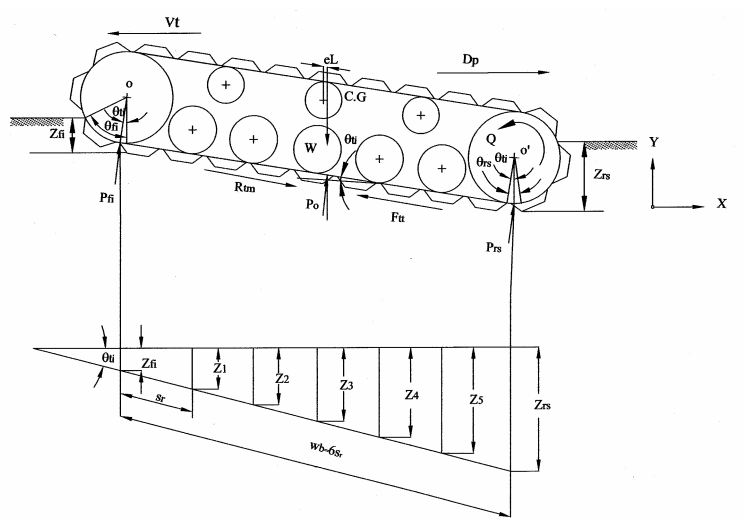

Fig. 2: Sinkage of the Track System for the Vehicle During Traversing on Peat Terrain at 10\% Slippage

by locating vehicle C.G at rearward of the track mid point, the vehicle will traverse on the specified terrain by making an angle $\theta_{\mathrm{ti}}$. Consequently, the track entry and exit angle at the front idler $\theta_{\mathrm{fi}}$ and rear sprocket $\theta_{\mathrm{rs}}$, the reaction pressure at the front idler $\mathrm{P}_{\mathrm{fi}}$, main straight part $P_{o}$ and rear sprocket $P_{r s}$ and the sinkage of the front idler $\mathrm{z}_{\mathrm{fi}}$, main straight part $\mathrm{z}_{\mathrm{mp}}$ and rear sprocket $\mathrm{z}_{\mathrm{rs}}$ and tangential force will reveal different value due to the different amount of slippage at each of the grouser positions of the rigid link tracks at the bottom track elements of the front idler $i_{\text {fi }}$, main straight parts $i_{m p}$ and rear sprocket $i_{\text {rs }}$ as shown in (Fig. 1).

The following assumptions are made in order the equation used in the mathematical modelling to be valided:

* Vehicle theoritical speed is considered to be 10 $\mathrm{km} \mathrm{h}^{-1}$ on zero slop terrain based on various offroad operation ASAE D497.3 NOV96, ASAE standard [1].

* Vehicle total weight is considered to be $19.62 \mathrm{kN}$ with payload of $9.81 \mathrm{kN}$ based on the in-field maximum fresh bounces collection practiced.

* Vehicle's track critical sinkage is considered to be $0.1 \mathrm{~m}$ based on experimental data on Sepang Peat terrain Ataur et al. [2].

* Aerodynamic resistance has been neglected due to the low operating speed.
* Vehicle's belly drag is considered to be zero since the vehicle hull is not in contact with the terrain.

* Vehicle speed fluctuation is considered to be $2.75 \%$ based on Wong [3].

* Road-wheel spacing is considered to be $0.245 \mathrm{~m}$ to ensure good drawbar performance based on Wong [3].

Amount of Sinkage: When the tracked vehicle will run on peat terrain with non-uniform pressure distribution, the vehicle track will move forward at speed of $\mathrm{v}_{\mathrm{t}}$ by making an angle $\theta_{\mathrm{ti}}$ with the terrain. The result in sinkages of the front idler $\mathrm{z}_{\mathrm{fi}}$, track main straight part $\mathrm{Z}_{\mathrm{mp}}$ and rear sprocket $\mathrm{Z}_{\mathrm{rs}}$, will have different values as shown in Fig. 2. In this case, the sinkage of the front idler is less significant but the average sinkages of the tracked main straight part and the sinkage of the rear sprocket are more significant for the performance of the vehicle.

For the sinkage of the front idler, the relationship between the front idler sinkage $z_{\mathrm{fi}}$ and reaction force $\mathrm{P}_{\mathrm{fi}}$ the stiffness of the peat surface mat $\mathrm{m}_{\mathrm{m}}$ and underlying peat $\mathrm{k}_{\mathrm{p}}$ can be modelled by simplifying equation of Wong [4]:

$z_{\mathrm{fi}}=\frac{-\left(\frac{k_{\mathrm{p}} D_{\text {hi }}}{4 \mathrm{~m}_{\mathrm{m}}}\right) \pm \sqrt{\left[\left(\frac{\mathrm{k}_{\mathrm{p}} \mathrm{D}_{\mathrm{hi}}}{4 \mathrm{~m}_{\mathrm{m}}}\right)^{2}+\frac{\mathrm{D}_{\mathrm{hif}} \mathrm{p}_{\mathrm{fi}}}{\mathrm{m}_{\mathrm{m}}}\right]}}{2}$

with $\mathrm{D}_{\text {hfi }}=\frac{4 \mathrm{BL}_{\mathrm{fib}}}{2\left(\mathrm{~L}_{\mathrm{fib}}+\mathrm{B}\right)}$

For the sinkage of the rear sprocket, the relationship between the rear sprocket sinkage $\mathrm{z}_{\mathrm{rs}}$ and reaction force $\mathrm{P}_{\mathrm{rs}}$ in a similar way:

$z_{r s}=\frac{-\left(\frac{k_{p} D_{h r s}}{4 m_{m}}\right) \pm \sqrt{\left[\left(\frac{k_{p} D_{h r s}}{4 m_{m}}\right)^{2}+\frac{D_{h r s} p_{r s}}{m_{m}}\right]}}{2}$

with ${ }_{\mathrm{D}_{\mathrm{hrs}}}=\frac{4 \mathrm{BL}_{\mathrm{rsb}}}{2\left(\mathrm{~L}_{\mathrm{rsb}}+\mathrm{B}\right)}$

The sinkage of the $1^{\text {st }}$ to $5^{\text {th }}$ road-wheel can be computed using the following equations:

$\mathrm{z}_{\mathrm{n}}=\mathrm{z}_{\mathrm{fi}}+\mathrm{ns}_{\mathrm{r}}\left(\sin \theta_{\mathrm{ti}}\right)$

The sinkage of the main straight part track element can be computed by taking average of the $1^{\text {st }}$ to $5^{\text {th }}$ roadwheel sinkage as following equation:

$\mathrm{z}_{\mathrm{mp}}=\frac{1}{\mathrm{n}} \sum_{\mathrm{n}}^{1} \mathrm{z}_{\mathrm{n}}$

where, $\mathrm{n}$ equals to $1 \sim 5$.

Track Entry and Exit Angle: The basic concept to the determination of the vehicle trim angle, track entry and 
exit angle is to understand the impact of all the individual angle on vehicle tractive performance when the vehicle traverse on peat terrain with non-uniform pressure distribution as shown in (Fig. 2). For the vehicle trim angle, the relationship between the vehicle trim angle $\theta_{\mathrm{ti}}$ with the terrain, the sinkage of the front idler $z_{\mathrm{fi}}$ and rear sprocket $\mathrm{z}_{\mathrm{rs}}$ and the track ground contact length $\mathrm{L}$ can be modelled by the following equation:

$$
\theta_{\mathrm{ti}}=\arcsin \left(\frac{\mathrm{z}_{\mathrm{rs}}-\mathrm{z}_{\mathrm{fi}}}{\mathrm{L}}\right)
$$

For the track entry angle at the front idler, the relationship between the entry angle of the front idler $\theta_{\mathrm{fi}}$, vehicle trim angle $\theta_{\mathrm{ti}}$, the sinkage of the front idler $\mathrm{z}_{\mathrm{fi}}$ and the radius of the front idler $\mathrm{R}_{\mathrm{fi}}$ can be modelled by the following equation:

$$
\theta_{\mathrm{fi}}=\arccos \left(\cos \theta_{\mathrm{ti}}-\frac{\mathrm{z}_{\mathrm{fi}}}{\mathrm{R}_{\mathrm{fi}}}\right)
$$

For the exit angle of the track at rear sprocket, the relationship between the track exit angle $\theta_{\mathrm{rs}}$, the sinkage of the front idler $z_{\mathrm{fi}}$ and rear sprocket $z_{\mathrm{rs}}$, the radius of the sprocket $R_{r s}$ and the track ground contact length $L$ can be modeled by the following equation:

$$
\theta_{\mathrm{rs}}=\arcsin \left(\frac{\mathrm{z}_{\mathrm{rs}}-\mathrm{z}_{\mathrm{fi}}}{\mathrm{L}}\right)+\arccos \left[\frac{\mathrm{R}_{\mathrm{rs}}}{{\sqrt{\left\{\mathrm{R}_{\mathrm{rs}}^{2}-\left(\mathrm{z}_{\mathrm{rs}}^{2}-\mathrm{z}_{\mathrm{fi}}^{2}\right)\right\}}}^{2}}\right]
$$

Amount of Slippage: The slippage is one of a functional parameter for the vehicle traction mechanism which is the mainly function of terrain sinkage parameters: surface mat stiffness $\mathrm{m}_{\mathrm{m}}$ and underlying peat stiffness $k_{p}$, terrain hydraulic diameters $D_{h}$, vehicle normal load $\mathrm{W}$, sinkage of the vehicle $\mathrm{z}$, vehicles track entry angle $\theta_{\mathrm{fi}}$ and exit angle $\theta_{\mathrm{rs}}$. It will reveal different value at the bottom track part of front idler, main straight part and rear sprocket if the vehicle traverses on the unprepared peat terrain with non-uniform ground pressure distribution. Therefore, it is important to compute the slippage of the front idler, track main straight part and rear sprocket separately for examining the vehicle performance over the peat terrain.

For the slippage of the ground contact track of front idler, the relationship between the front idler slippage $\mathrm{i}_{\mathrm{fi}}$ , the slip ratio $i$, the entry angle of the track at front idler $\theta_{\mathrm{fi}}$, the track ground contact length $\mathrm{L}$ and front idler radius $\mathrm{R}_{\mathrm{fi}}$ can be modeled by the following equation :

$$
\mathrm{i}_{\mathrm{fi}}=\left(\frac{\mathrm{R}_{\mathrm{fi}}}{\mathrm{L}_{\mathrm{fi}}}\right) \int_{0}^{0_{\mathrm{fi}}}\left\{1-(1-\mathrm{i}) \cos \left(\theta+\theta_{\mathrm{ti}}\right)\right\} \mathrm{d} \theta
$$

By integrating the Eq.(8), the following equation can be found:

$\mathrm{i}_{\mathrm{fi}}=\left(\frac{\mathrm{R}_{\mathrm{fi}}}{\mathrm{L}_{\mathrm{fi}}}\right)_{\mathrm{fi}}\left[\theta_{\mathrm{fi}}-(1-\mathrm{i})\left\{\sin \left(\theta_{\mathrm{fi}}+\theta_{\mathrm{ti}}\right)-\sin \theta_{\mathrm{ti}}\right\}\right]$

with $\mathrm{L}_{\mathrm{fi}}=\mathrm{R}_{\mathrm{fi}}\left(\theta_{\mathrm{fi}}+\theta_{\mathrm{ti}}\right)$

For the slippage of the ground contact track of rear sprocket, the relationship between the slippage of rear sprocket $i_{r s}$ and front idler $i_{\text {fi }}$, rear sprocket radius $R_{r s}$, the track entry angle $\theta_{\mathrm{fi}}$, and exit angle $\theta_{\mathrm{rs}}$ can be modeled by the following equation:

$$
\begin{aligned}
& \mathrm{i}_{\mathrm{rs}}=\left(\frac{\mathrm{R}_{\mathrm{fi}}}{\mathrm{L}_{\mathrm{fi}}}\right) \int_{0}^{\theta_{\mathrm{fi}}}\left\{1-(1-\mathrm{i}) \cos \left(\theta+\theta_{\mathrm{ti}}\right)\right\} \mathrm{d} \theta+ \\
& \mathrm{i}\left(\frac{\mathrm{L}_{\mathrm{rs}}}{\mathrm{L}}\right)+\left(\frac{\mathrm{R}_{\mathrm{rs}}}{\mathrm{L}_{\mathrm{rs}}}\right) \int_{0}^{\theta_{\mathrm{rs}}}\left\{1-(1-\mathrm{i}) \cos \left(\theta+\theta_{\mathrm{ti}}\right)\right\} \mathrm{d} \theta
\end{aligned}
$$

By integrating the Eq.(10), the following equation can be found:

$i_{r s}=i_{f i}+i\left(\frac{L_{r s}}{L}\right)+\left(\frac{R_{r s}}{L_{r s}}\right)\left[\theta_{r s}+(1-i) \sin \left(\theta_{r s}+\theta_{t i}\right)-\sin \theta_{t i}\right]$

with $\mathrm{L}_{\mathrm{rs}}=\mathrm{R}_{\mathrm{rs}}\left(\theta_{\mathrm{rs}}+\theta_{\mathrm{ti}}\right)$

Tractive Effort: The tractive effort of the tracked vehicle with non-uniform ground pressure distribution during straight running is developed not only on the ground contact part of the track but also on the side parts of the ground contact track grouser. Furthermore, the tractive effort is developed not only on the main part of the ground contact track but also on parts of front idler and rear sprocket as shown in Fig. 3. The track initial tension $\mathrm{T}_{\text {in }}$ is assumed to be $12 \%$ of the total vehicle weight $19.62 \mathrm{kN}$ including $5.88 \mathrm{kN}$ payload and is assumed to be constant in every point of the track system in order to avoid the track deflection between the consecutive road-wheel and supporting rollers. The traction mechanics of the track bottom part of the front idler, road-wheels and rear sprocket are different due to its different angle of entry and exit. It is also different due to the different sinkage of the track front idler, main straight part and rear sprocket when the vehicle will traverse on the unprepared peat terrain with nonuniform ground pressure distribution. Therefore, it is important to compute the traction of the individual components bottom track segment, separately. For the tractive effort of tracked vehicle, the relationship between the tractive effort of the vehicle $\mathrm{F}$, shearing strength of the peat terrain $\tau$, track width $B$, track ground contact length $\mathrm{L}$, vehicle normal stress $\sigma$, terrain cohesiveness $c$, terrain internal friction angle $\varphi$, slippage of the vehicle $\mathrm{i}$, shear displacement $\mathrm{j}$, shear 


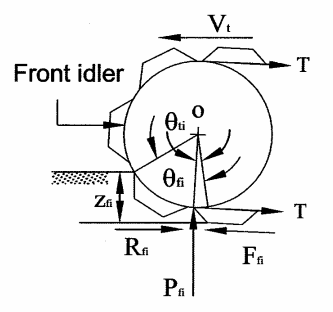

(a)

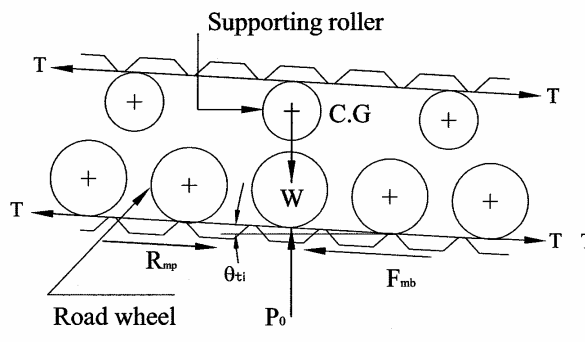

(b)

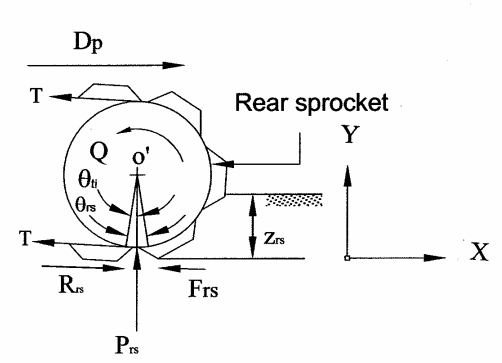

(c)

Fig. 3: Force Diagram on the Track System Segmented Components (a) Front Idler, (b) Track Main Straight Part and (c) Rear Sprocket

deformation modulus $\mathrm{K}_{\mathrm{w}}$, and maximum shearing strength of the terrain $\tau_{\max }$ under the bottom of the track on peat terrain for uniform pressure distribution can be modeled using the following equation of Bekker given first in general formulation:

$$
F=2 B \int_{0}^{L} \tau d x
$$

with $\tau=\tau_{\max }\left(\frac{\mathrm{j}_{\mathrm{x}}}{\mathrm{K}_{\mathrm{w}}}\right) \exp \left(1-\frac{\mathrm{j}_{\mathrm{x}}}{\mathrm{K}_{\mathrm{w}}}\right)$

Where, $\tau_{\max }=(\mathrm{c}+\sigma \tan \varphi)$ and $\mathrm{j}_{\mathrm{x}}=\mathrm{ix}$, By integrating the Eq. (12), the tractive effort of the vehicle for peat terrain can be computed as follows:

$$
\mathrm{F}=2 \mathrm{~A}(\mathrm{c}+\sigma \tan \varphi)\left[\frac{\mathrm{K}_{\mathrm{w}}}{\mathrm{iL}} \mathrm{e}^{1}-\left(1+\frac{\mathrm{K}_{\mathrm{w}}}{\mathrm{iL}}\right) \exp \left(1-\frac{\mathrm{iL}}{\mathrm{K}_{\mathrm{w}}}\right)\right]
$$

For the tractive effort developed at the track ground contact element of front idler as (Fig. 3a), the relationship between the tractive effort $\mathrm{F}_{\mathrm{fi}}$ developed at the ground contact track, track ground contact length L, track width $\mathrm{B}$, terrain cohesiveness c, normal stress $\sigma$, shear stress $\tau$, shear deformation modulus $K_{w}$, slippage of the track-terrain interfaces $\mathrm{i}$ and shear displacement $\mathrm{j}_{\mathrm{x}}$ can be modeled by the following equation:

$$
F_{\text {fib }}=2 B L_{\text {fib }}(c+\sigma \tan \varphi)\left[\frac{e^{1} K_{\text {wfi }}}{i_{\text {fi }} L_{\text {fib }}}-\left(1+\frac{K_{\text {wi }}}{i_{\text {fi }} L_{\text {fib }}}\right) \exp \left(1-\frac{i_{\text {fi }} L_{\text {fib }}}{K_{\text {wfi }}}\right)\right]
$$

with $\mathrm{L}_{\mathrm{fib}}=\mathrm{R}_{\mathrm{fi}}\left(\theta_{\mathrm{fi}}+\theta_{\mathrm{ti}}\right)$

Similarly the tractive effort for the bottom ground contact part of main straight track elements as (Fig. 3b) can be modeled by the following equation:
$\mathrm{F}_{\mathrm{mb}}=2 \mathrm{BL}(\mathrm{c}+\sigma \tan \varphi)\left[\frac{\mathrm{e}^{1} \mathrm{~K}_{\mathrm{wmb}}}{\mathrm{i}_{\mathrm{mb}} \mathrm{L}}-\left(1+\frac{\mathrm{K}_{\mathrm{wmb}}}{\mathrm{i}_{\mathrm{mb}} \mathrm{L}}\right) \exp \left(1-\frac{\mathrm{i}_{\mathrm{mb}} \mathrm{L}}{\mathrm{K}_{\mathrm{wmb}}}\right)\right]$

with $i_{\mathrm{mb}}=\frac{\mathrm{i}_{\mathrm{fi}}+\mathrm{i}_{\mathrm{rs}}}{2}$

Similarly the tractive effort for the bottom ground contact part of the rear sprocket track elements as (Fig. 3c) can be modeled by the following equation:

$\mathrm{F}_{\mathrm{rsb}}=2 \mathrm{~B} \mathrm{~L}_{\mathrm{rbb}}(\mathrm{c}+\sigma \tan \varphi)\left[\frac{\mathrm{e}^{1} \mathrm{~K}_{\mathrm{wrs}}}{\mathrm{i}_{\mathrm{rs}} \mathrm{L}_{\mathrm{rsb}}}-\left(1+\frac{\mathrm{K}_{\mathrm{wrs}}}{i_{\mathrm{rs}} \mathrm{L}_{\mathrm{rsb}}}\right) \exp \left(1-\frac{\mathrm{i}_{\mathrm{rs}} \mathrm{L}_{\mathrm{rsb}}}{\mathrm{K}_{\mathrm{wrs}}}\right)\right]$

with $\mathrm{L}_{\mathrm{rsb}}=\mathrm{R}_{\mathrm{rs}}\left(\theta_{\mathrm{rs}}+\theta_{\mathrm{ti}}\right)$

The traction mechanics of the track at the side of the grouser is highly significant on the development of vehicle traction if the vehicle sinkage is more than the grouser height [4]. In this study, it is assumed that the sinkage of the vehicle is more than the grouser height of the track. For non-uniform ground pressure distribution of the vehicle, the traction of the side of track ground contact part which is highly significant due to its different sinkage of front idler, track main straight part and rear sprocket. For the tractive effort developed at the side of the ground contact front idler track element, the relationship between the tractive effort $F_{s}$ developed at the side of the track ground contact part, track grouser height $\mathrm{H}$, track ground contact length L, terrain cohesiveness c, normal stress $\sigma$, shear stress $\tau$, shear deformation modulus $\mathrm{K}_{\mathrm{w}}$ and slippage $\mathrm{i}$ of the vehicle trackterrain interfaces can be modeled by the following equation:

$\mathrm{F}_{\text {fis }}=4 \mathrm{HL}_{\text {fib }}(\mathrm{c}+\sigma \tan \varphi) \cos \alpha\left[\frac{\mathrm{e}^{1} \mathrm{~K}_{\mathrm{wfi}}}{\mathrm{i}_{\mathrm{fi}} \mathrm{L}_{\mathrm{fib}}}-\left(1+\frac{\mathrm{K}_{\mathrm{wfi}}}{\mathrm{i}_{\mathrm{fi}} \mathrm{L}_{\text {fib }}}\right) \exp \left(1-\frac{\mathrm{i}_{\mathrm{fib}} \mathrm{L}_{\text {fib }}}{\mathrm{K}_{\mathrm{wfi}}}\right)\right]$ 

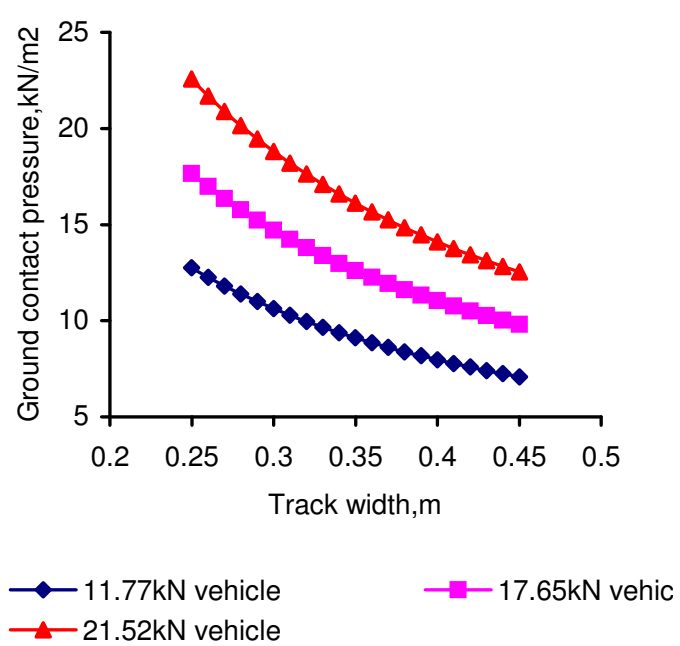

(a)

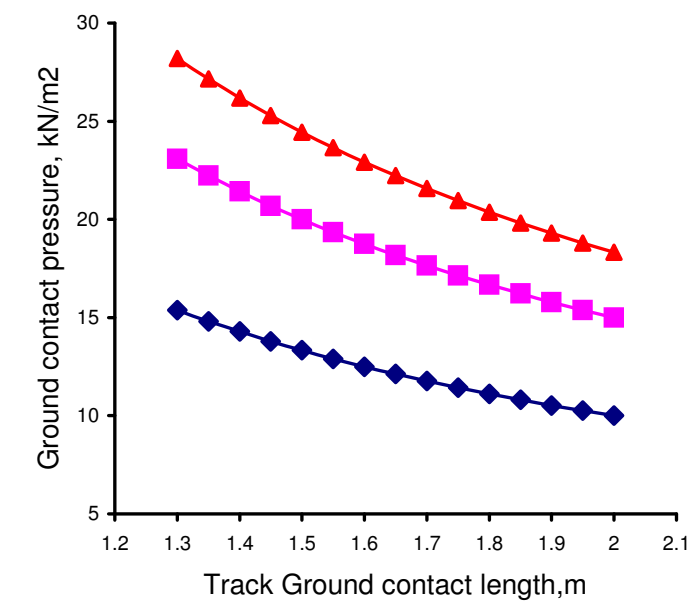

$\longrightarrow 11.77 \mathrm{kN}$ vehicle $\longrightarrow 17.65 \mathrm{kN}$ vehicle $\longrightarrow 21.52 \mathrm{kN}$ vehicle

(b)

Fig. 4: Variation of Ground Pressure Distribution with (a) Variation of Track width at Constant Track Ground Contact Length of $200 \mathrm{~cm}$ and (b) Variation of Track Ground Contact Length at Constant Track Width of $30 \mathrm{~cm}$

with $\alpha=\arctan \left[\cot \left(\frac{H}{B}\right)\right]$

Similarly the tractive effort for the side of the ground contact part of main straight track element can be modeled by the following equation:

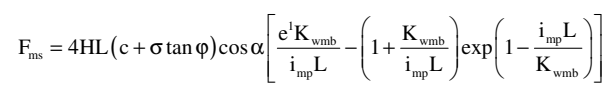

Similarly the tractive effort for the side of the ground contact part of rear sprocket track element can be modeled by the following equation:

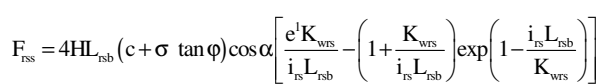

Therefore, the total thrust of the rubber track vehicle can be computed as the sum of the individual thrust components by:

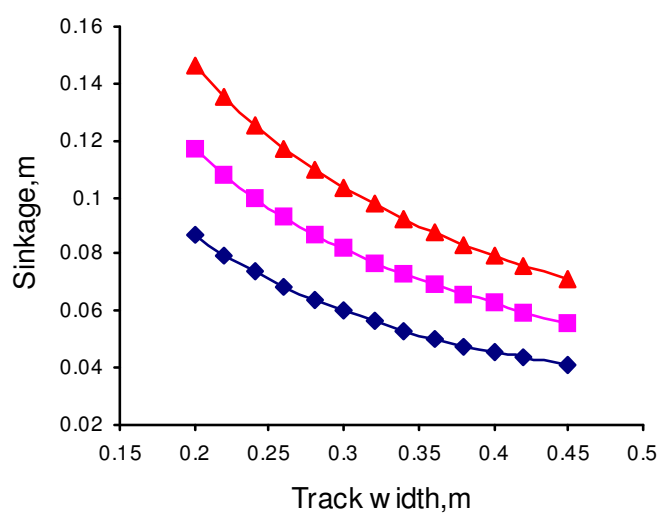

$\multimap 11.77 \mathrm{kN}$ vehicle $\longrightarrow-21.52 \mathrm{kN}$ vehicle

(a)

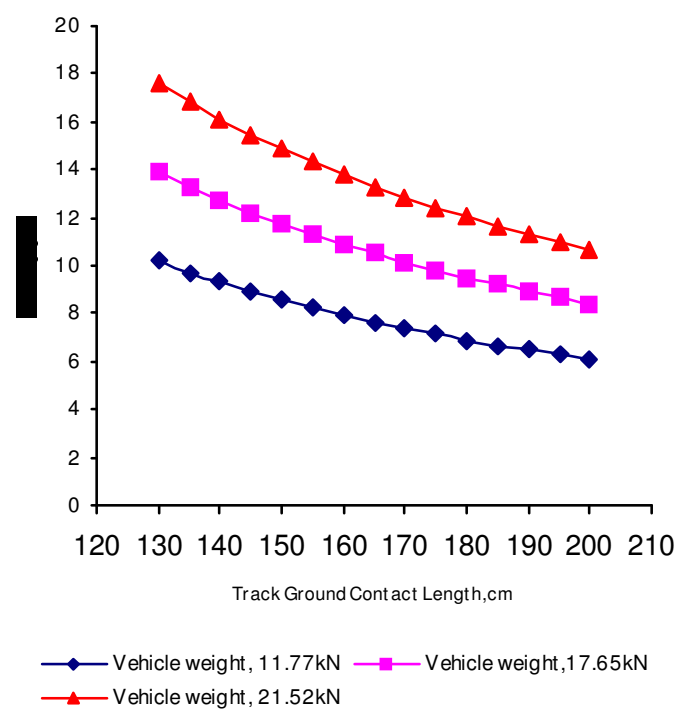

(b)

Fig. 5: Variation of Vehicle Sinkage with (a) Variation of Track Width at Constant Track Ground Contact Length of $200 \mathrm{~cm}$ and (b) Variation of Track Ground Contact Length at Constant Track Width of $30 \mathrm{~cm}$

$\mathrm{F}_{\mathrm{tt}}=\mathrm{F}_{\text {fib }}+\mathrm{F}_{\mathrm{rsb}}+\mathrm{F}_{\mathrm{mb}}+\mathrm{F}_{\text {fis }}+\mathrm{F}_{\mathrm{rss}}+\mathrm{F}_{\mathrm{mps}}$

Motion Resistance: The motion resistance of a track vehicle can be splited into internal and external motion resistance. The main contributions to the internal motion resistance are located over the track-suspension 
system and are given by frictional losses in track pins, between the driving sprocket teeth and the track, in front idler and roadwheel bearings and by the rolling resistance of the roadwheel on the track. The external motion resistance is mainly due to the vehicle terrain interaction, in particularly to terrain compaction and has a major influence on the mobility of the vehicle. It should be properly determined from horizontal component of the normal pressure acting along the track. When the vehicle traverse on peat terrain with uniform pressure distribution, the sinkage of the moving components of the track such as front idler, track main straight part and rear sprocket will be the same. Therefore, it is not important to compute the motion resistance due to soil compaction and bulldozzing effect for the individual component of the track in order to examine the performance of the vehicle.

For the motion resistance of the vehicle due to terrain compaction, the relationship between the motion resistance of the vehicle due to terrain compaction $R_{c}$, the ground contact length $\mathrm{L}$, track width $\mathrm{B}$, sinkage of the vehicle $\mathrm{z}$, stiffness of peat surface mat $\mathrm{m}_{\mathrm{m}}$ and underlying peat $\mathrm{k}_{\mathrm{p}}$ can be modeled by simplifying the equation of Wong [4] given first in general formulation:

$$
\mathrm{R}_{\mathrm{c}} \mathrm{L}=2 \mathrm{~B} \mathrm{~L} \int_{0}^{2} \mathrm{pdz}
$$

with $P=\left(k_{p} z+\frac{4}{D_{h}} m_{m} z^{2}\right)$

By integrating the equation (21), the motion resistance equation can given by the following equation:

$\mathrm{R}_{\mathrm{c}}=2 \mathrm{~B}\left(\frac{\mathrm{k}_{\mathrm{p}} \mathrm{z}^{2}}{2}+\frac{4}{3 \mathrm{D}_{\mathrm{h}}} \mathrm{m}_{\mathrm{m}} \mathrm{z}^{3}\right)$

When the same vehicle as shown in Fig. 1, will traverse on the peat terrain with non-uniform pressure distribution, the vehicle individual component such as front idler, main straight part and rear sprocket motion resistance reveal different value due to the variation of sinkage. Therefore, it is important to compute the motion resistance of the individual component in order to total-up the motion resistance for understanding the vehicle performance. For the motion resistance of the vehicle due to terrain compaction, the relationship between the motion resistance of the vehicle due to terrain compaction $\mathrm{R}_{\mathrm{c}}$, the ground contact length of the track of front idler, main straight part and rear sprocket $\mathrm{L}_{\mathrm{fi}}, \mathrm{L}_{\mathrm{mp}}$ and $\mathrm{L}_{\mathrm{rs}}$, respectively, the hydraulic diameter of track ground contact length of the track of front idler, main straight part and rear sprocket are $\mathrm{D}_{\mathrm{fi}}, \mathrm{D}_{\mathrm{mp}}$ and $\mathrm{D}_{\mathrm{rs}}$, respectively, track width $\mathrm{B}$, sinkage of the track of front idler, track main straight part and track of rear sprocket $\mathrm{z}_{\mathrm{fi}}$, stiffness of peat surface mat $\mathrm{m}_{\mathrm{m}}$ and underlying peat $\mathrm{k}_{\mathrm{p}}$ can be modeled by the following equation:
$\mathrm{R}_{\mathrm{c}}=(2 \mathrm{~B})\left[\begin{array}{l}\left(\frac{\mathrm{L}_{\mathrm{fi}}}{\mathrm{L}}\right)\left(\frac{\mathrm{k}_{\mathrm{p}} \mathrm{z}_{\mathrm{fi}}{ }^{2}}{2}+\frac{4}{3 \mathrm{D}_{\mathrm{hii}}} \mathrm{m}_{\mathrm{m}} \mathrm{z}_{\mathrm{fi}}{ }^{3}\right)+\left(\frac{\mathrm{L}_{\mathrm{mp}}}{\mathrm{L}}\right)\left(\frac{\mathrm{k}_{\mathrm{p}} \mathrm{z}_{\mathrm{mp}}{ }^{2}}{2}+\frac{4}{3 \mathrm{D}_{\mathrm{hmp}}} \mathrm{m}_{\mathrm{m}} \mathrm{Z}_{\mathrm{mp}}{ }^{3}\right) \\ +\left(\frac{\mathrm{L}_{\mathrm{r}}}{\mathrm{L}}\right)\left(\frac{\mathrm{k}_{\mathrm{p}} \mathrm{z}_{\mathrm{rs}}{ }^{2}}{2}+\frac{4}{3 \mathrm{D}_{\mathrm{hrs}}} \mathrm{m}_{\mathrm{m}} \mathrm{z}_{\mathrm{rs}}{ }^{3}\right)\end{array}\right]$

with

$$
D_{h f i}=\frac{4 B L_{f i}}{2\left(L_{f i}+B\right)}, \quad D_{h m p}=\frac{4 B L_{m p}}{2\left(L_{m p}+B\right)}
$$

and

$\mathrm{D}_{\mathrm{hrs}}=\frac{4 \mathrm{BL}_{\mathrm{rs}}}{2\left(\mathrm{~L}_{\mathrm{rs}}+\mathrm{B}\right)}$

For the motion resistance of the vehicle due to bull dozing effect front idler track element, the relationship between the motion resistance of the vehicle due to bull dozing effect $R_{\text {fib }}$, the bulk density of the terrain $\gamma_{d}$, the internal frictional angle $\varphi$, track width $\mathrm{B}$ and terrain cohesiveness $\mathrm{c}$ can be modeled by the following equation of Wong [4]:

$\mathrm{R}_{\mathrm{fib}}=2 \mathrm{~B}\left[\gamma_{\mathrm{d}} \mathrm{z}_{\mathrm{fi}}{ }^{2} \tan ^{2}\left(45+\frac{\varphi}{2}\right)+\mathrm{cz}_{\mathrm{fi}} \tan \left(45+\frac{\varphi}{2}\right)\right]$

Simillarly the motion resistance for the main straight part track element can be modelled by the following equation:

$\mathrm{R}_{\mathrm{msb}}=2 \mathrm{~B}\left[\gamma_{\mathrm{d}} \mathrm{z}_{\mathrm{mp}}{ }^{2} \tan ^{2}\left(45+\frac{\varphi}{2}\right)+\mathrm{cz}_{\mathrm{mp}} \tan \left(45+\frac{\varphi}{2}\right)\right]$

Simillarly the motion resistance for the rear sprocket track element can be modelled by the following equation:

$\mathrm{R}_{\mathrm{rsb}}=2 \mathrm{~B}\left[\gamma_{\mathrm{d}} \mathrm{z}_{\mathrm{rs}}{ }^{2} \tan ^{2}\left(45+\frac{\varphi}{2}\right)+c \mathrm{z}_{\mathrm{rs}} \tan \left(45+\frac{\varphi}{2}\right)\right]$

The motion resistance due to frictional losses of the vehicle moving components can be predicted using the following equation by Wong [4]:

$\mathrm{R}_{\text {in }}=\left(\frac{\mathrm{W}}{10^{6}}\right)\left[222+3 \mathrm{v}_{\mathrm{t}}\right]$

The total motion resistance of the rubber track vehicle can be computed as the sum of the individual motion resistance components by:

$\mathrm{R}_{\mathrm{tm}}=\mathrm{R}_{\mathrm{c}}+\mathrm{R}_{\mathrm{in}}+\mathrm{R}_{\mathrm{fib}}+\mathrm{R}_{\mathrm{rbb}}+\mathrm{R}_{\mathrm{mpb}}$

Torque of the Sprocket: Sprocket acts as drive wheel of the vehicle. It powers the track to propel. When torque is applied at the sprocket it starts driving the track and the vehicle starts moving. A frictional torque appears in the bearings of moving element of the track system, resisting the vehicle motion. The forces appear at the track interface due to the terrain compaction and vehicle bulldozing effect, resisting the vehicle motion. Therefore, the vehicle needs to develop sufficient 
Table 1: Peat Terrain Parameters

\begin{tabular}{lllll}
\hline Parameters & \multicolumn{1}{c}{ Un-drained } & \multicolumn{2}{c}{ Drained } \\
\hline & Mean value & SD & Mean value & SD \\
\hline$\omega,(\%)$ & 83.51 & - & 79.58 & - \\
$\gamma_{\mathrm{d}},\left(\mathrm{kN} \mathrm{m}^{-3}\right)$ & 1.53 & 0.59 & 1.82 & 0.78 \\
$\left.\mathrm{c}, \mathrm{kN} \mathrm{m}^{-2}\right)$ & 1.36 & 0.21 & 2.73 & 0.39 \\
$\varphi,\left(\right.$ degree $\left.^{2}\right)$ & 23.78 & 4.56 & 27.22 & 2.19 \\
$\mathrm{~K}_{\mathrm{w}},(\mathrm{cm})$ & 1.19 & 0.10 & 1.12 & 0.17 \\
$\mathrm{~m}_{\mathrm{m}},\left(\mathrm{kN} \mathrm{m}^{-3}\right)$ & 27.07 & 13.47 & 41.79 & 13.37 \\
$\mathrm{k}_{\mathrm{p}},\left(\mathrm{kN} \mathrm{m}^{-3}\right)$ & 224.38 & 52.84 & 356.8 & 74.27 \\
\hline
\end{tabular}

SD: Standard deviation $\quad$ Source: Ataur et al. [2].

Table 2: Variation of Drawbar Pull

\begin{tabular}{|c|c|c|c|}
\hline \multirow[t]{2}{*}{ Slippage (\%) } & \multicolumn{2}{|c|}{ Drawbar pull $(\mathrm{kN})$} & \\
\hline & Predicted & Measured & $\begin{array}{l}\text { Variations } \\
=(\text { Predicted-Measured })\end{array}$ \\
\hline 1 & 0.64748 & 0.490 & 0.15698 \\
\hline 2 & 0.74872 & 0.54936 & 0.19936 \\
\hline 3 & 1.56854 & 1.37340 & 0.19514 \\
\hline 4 & 2.14731 & 1.82466 & 0.32265 \\
\hline 5 & 2.76129 & 1.96200 & 1.96200 \\
\hline 6 & 3.58242 & 3.58242 & 1.22802 \\
\hline 7 & 3.86117 & 2.74680 & 1.11437 \\
\hline 8 & 4.33110 & 2.94300 & 1.02810 \\
\hline 9 & 4.53494 & 3.67875 & 1.19954 \\
\hline 10 & 4.70333 & 3.67875 & 1.02458 \\
\hline 12 & 5.23689 & 4.51260 & 1.22733 \\
\hline 15 & 5.73993 & 4.51260 & 1.22733 \\
\hline 20 & 6.38425 & 4.90500 & 1.47925 \\
\hline 25 & 6.93215 & 5.39550 & 1.53665 \\
\hline 30 & 7.32373 & 6.37650 & 0.94723 \\
\hline 35 & 7.44424 & 6.86700 & 0.57724 \\
\hline 40 & 7.58895 & 7.65180 & -0.06285 \\
\hline 45 & 7.71568 & 7.93850 & -0.22282 \\
\hline 50 & 7.76219 & 8.21950 & -0.45731 \\
\hline
\end{tabular}

Table 3: Variation of Tractive Efficiency

\begin{tabular}{|c|c|c|c|}
\hline Slippage (\% & & tive efficier & \\
\hline & Predicted & Measured & $\begin{array}{l}\text { Variations } \\
=\text { (Predicted-Measured) }\end{array}$ \\
\hline 1 & 27.5174 & 31.0 & -3.48263 \\
\hline 2 & 61.5109 & 59.0 & 2.51085 \\
\hline 3 & 69.5897 & 66.0 & 3.58967 \\
\hline 4 & 70.8440 & 67.0 & 3.84503 \\
\hline 5 & 70.9720 & 68.0 & 2.97202 \\
\hline 6 & 71.6858 & 69.5 & 2.18581 \\
\hline 7 & 71.6643 & 70.6 & 1.06426 \\
\hline 8 & 71.3393 & 71.0 & 0.33929 \\
\hline 9 & 70.6963 & 70.0 & 0.69627 \\
\hline 10 & 70.0198 & 69.0 & 1.01948 \\
\hline 12 & 69.4179 & 68.0 & 1.41792 \\
\hline 15 & 66.3930 & 66.0 & 0.39298 \\
\hline 20 & 62.7069 & 60.0 & 2.70693 \\
\hline 25 & 59.0370 & 55.0 & 4.03701 \\
\hline 30 & 55.1446 & 53.0 & 2.14458 \\
\hline 35 & 51.3733 & 45.0 & 6.37326 \\
\hline 40 & 47.5176 & 48.0 & -0.48245 \\
\hline 45 & 43.6120 & 46.0 & -2.38804 \\
\hline 50 & 39.6850 & 35.0 & 4.68502 \\
\hline
\end{tabular}

tractive effort after developing shear stress at the trackterrain interface in order to move forward with overcoming all of the motion resistance. The tension in each track segment is not effecting the torque of the vehicle motion since it is assumed to be constant due to the geometrical arrangement of the road-wheel and initial tension equals to $12 \%$ total weight of the vehicle.
For the torque of the sprocket, the relationship between the torque of the sprocket $Q$, vehicle total tractive effort $F_{t t}$, total motion resistance $R_{t m}$, Sprocket radius $R_{r s}$, track grouser height $\mathrm{H}$, vehicle total weight $\mathrm{W}$ and vehicle normal reaction force $F_{n}$ and track ground contact length $\mathrm{L}$ can be modeled by using the following equation:

The torque of the track vehicle rear sprocket as shown in (Fig. 1) can be determined using the following equation:

$$
\begin{aligned}
& \mathrm{Q}=\mathrm{F}_{\mathrm{tt}}\left(\mathrm{R}_{\mathrm{rs}}+\mathrm{H}\right)-\mathrm{R}_{\mathrm{tm}}\left(\mathrm{R}_{\mathrm{rs}}+\mathrm{H}_{\mathrm{fi}}\right)+\mathrm{W}\left(\mathrm{h}_{\mathrm{cg}}-\mathrm{R}_{\mathrm{rs}}\right) \sin \theta_{\mathrm{ti}} \\
& -\mathrm{WL}\left(\frac{1}{2}-\mathrm{e}_{\mathrm{i}}\right) \cos \theta_{\mathrm{ti}}+\mathrm{F}_{\mathrm{n}} \mathrm{L}\left(\frac{1}{2}-\mathrm{e}_{\mathrm{i}}\right) \cos \theta_{\mathrm{ti}} \\
& \text { with } \mathrm{F}_{\mathrm{n}}=\frac{\mathrm{W}-\mathrm{F}_{\mathrm{tt}} \sin \theta_{\mathrm{ti}}}{\cos \theta_{\mathrm{ti}}}
\end{aligned}
$$

Sprocket Power Requirement: For the effective sprocket power, the relationship between the sprocket effective power $\mathrm{P}_{\mathrm{es}}$ that will be available to traverse the vehicle on the peat terrain with desired speed $\mathrm{N}_{\mathrm{rs}}$ can be modelled by the following equation:

$$
\mathrm{P}_{\mathrm{es}}=\left(\frac{1}{9550}\right)\left(\mathrm{QN}_{\mathrm{s}}\right)
$$

Engine Power: The effective engine power available at the transmission input shaft for developing the desired output torque at driven sprockets can be computed using the following equation:

$$
P_{e}=\left(\frac{1}{367.2}\right)\left(\frac{F_{t} v_{t}}{\mu_{t}}\right)
$$

Drawbar Power: The drawbar power is referred to as the potential productivity of the vehicle, that is, the rate which productive work may be done. It can be computed by using the following equation:

$P_{d}=\left(\frac{1}{367.2}\right)\left(D_{p} v_{a}\right)$

with $\mathrm{D}_{\mathrm{p}}=\mathrm{F}_{\mathrm{tt}}-\mathrm{R}_{\mathrm{tm}}$

Tractive Efficiency: Tractive efficiency is used to characterize the efficiency of track vehicle in transforming the engine power to the power available at the drawbar. It can be computed by using the following equation:

$\eta_{\mathrm{d}}=\frac{\mathrm{P}_{\mathrm{s}}}{\mathrm{P}_{\mathrm{e}}}(100 \%)$

Mathematical Model Validation: The drawbar pull and the tractive efficiency of the light peat protoype 
Kobuta Carrier RC20P track vehicle having a track size of $0.43 \mathrm{~m}$ width and $1.40 \mathrm{~m}$ track ground contact length and total weight of $25.95 \mathrm{kN}$ including payload $9.81 \mathrm{kN}$ and three pneumatic roadwheels on each track, operating on a peat terrain were predicted through simulation method. The predicted drawbar pull and tractive efficiency was compared with the measured data from the field tests provided by Malayisian Agricultural Research and Development Institute [5]. The variations predicted and measured drawbar pull and tractive efficiency of the Kobuta Carrier RC20P track vehicle are shown in Table 2 and 3.

In order to substantiate the validity of the simulation method the comparison were made based on the $\mathrm{T}$ test values that were found by the SAS analysis as shown in Table 4 and 5 . In Table 4 , the $\mathrm{T}$ values of 5.133 with $\mathrm{P}=$ 0.001 concluded that the variations between the predicted and measured drawbar pull is highly significant. While, the standard error values of 0.142 concluded that both of the predicted and measured drawbar pull are pretty tightly bunched together. The conclusion is further supported by the Table 5. In Table 5 , the $\mathrm{T}$ values of 3.24 with $\mathrm{P}=0.0045$ concluded that the variations of predicted and measured tractive efficiency is highly significant. While, the standard error values of 0.546 concluded that both of the predicted and measured tractive efficiency are pretty tightly bunched together. Therefore, the closed agreement between the predicted and measured drawbar pull and tractive efficiency substaintiates the validitity of the simulation model.

Vehicle Design Parameters Optimization: Tractive performance of the rigid link segmented rubber tracked vehicle has been computed with the computer simulation method based on the developing new mathematical model for undrained peat terrain. It appeared that the engine size and tractive performance of the vehicle on peat terrain vary with the variation of vehicle weight, track size including track ground contact length, width, pitch and grouser height, track entry and exit angle, idler diameter and location, sprocket diameter and location, road-wheel diameter, spacing and geometrical arrangement and location of center of gravity. Therefore, for the selection and optimization design parameters of the vehicle track size, idler diameter and location, sprocket diameter and location, number of road-wheel, road-wheel diameter, spacing and geometrical arrangement, ratio of the roadwheel spacing to track pitch, ratio of the sprocket diameter to track pitch,location of the center of gravity are taken into account. The optimization design parameters of the vehicle has been performed by using the microsoft Excel software with performing calculations, analysing informations and managing lists in speadsheets.
Track Width and Ground Contact Length: The length of the track in contact with the ground and the level of pressure within the ground are the most important factors that influenced tracked vehicle tractive performance. To evaluate the effects of track system configuration on vehicle ground pressure distribution and surface mat stiffness, it is important to study track ground contact length and width. Figure $4 \mathrm{a}$ and $4 \mathrm{~b}$ show that the vehicle ground pressure distribution decreases with increasing vehicle track ground contact length and width. The vehicles under consideration are traversing on a zero slope terrain with travel speed of $10 \mathrm{~km} \mathrm{~h}^{-1}$. From the field experiment on Sepang, it was found that the bearing capacity for the un-drained peat terrain was $17 \mathrm{kN} \mathrm{m}^{-2}$. It appears that if the ground contact pressure of the $19.62 \mathrm{kN}$ vehicle with a moderate payload of $5.89 \mathrm{kN}$ is limited to $16.35 \mathrm{kN} \mathrm{m}^{-2}$ by designing a track with ground contact area of $30 \times 2000 \mathrm{~mm}^{2}$ then the sinkage and external motion resistance of the vehicle will be low and tractive effort will be high, yielding desired travel speed of 10 $\mathrm{km} \mathrm{h}^{-1}$ and vehicle productivity.

Figure $5 \mathrm{a}$ and $5 \mathrm{~b}$ show that the sinkage of the vehicle decreases with increasing track width and track ground contact length. If the track size of the vehicles is limited to $300 \times 2000 \mathrm{~mm}^{2}$, then the sinkage of the $11.77,17.65$ and $21.52 \mathrm{kN}$ vehicles will be $61,81.8$ and $110 \mathrm{~mm}$, respectively. From the field experiment, it was found that the surface mat thickness of the Sepang peat terrain was $100 \mathrm{~mm}$, which will support the maximum load of the vehicle during static and dynamic as well. Therefore, if the vehicle sinkage is more than $100 \mathrm{~mm}$ the vehicle will sink rather than traverse. If the vehicle total weight is considered to $19.62 \mathrm{kN}$ and the track ground contact area to $300 \times 2000 \mathrm{~mm}^{2}$, the vehicle will traverse on the peat terrain with sinkage of $90 \mathrm{~mm}$ or $10 \%$ less than the Sepang peat terrain surface mat thickness and exit ground pressure of $16 \mathrm{kN} \mathrm{m}^{-2}$ or $6 \%$ less than the worst condition Sepang peat terrain bearing capacity. Based on the $19.62 \mathrm{kN}$ vehicle sinkage and ground contact pressure, it may be conclude that the vehicle will not in risk to traverse on peat terrain if the vehicle used the track ground contact area of $300 \times 2000 \mathrm{~mm}^{2}$. Therefore, the best choice to select the vehicle track ground contact area of $300 \times 2000 \mathrm{~mm}^{2}$ for the vehicle to produce the effective tractive performance.

The conclusion is further supported by the relation between the track size and motion resistance with keeping option either track width or track ground contact length could increase to adjust the track ground contact area for getting the desired vehicle ground contact pressure. Figure $6 \mathrm{a}$ and $\mathrm{b}$ show that the motion resistance coefficient of the vehicle increases with increasing track width and decreases with increasing track ground contact length. Figure 6a shows that the 
motion resistance coefficient increased $18.12 \%$ for $13.73 \mathrm{kN}$ vehicle, $16.99 \%$ for $17.65 \mathrm{kN}$ vehicle and $24.12 \%$ for $21.58 \mathrm{kN}$ vehicle with increasing the track width from 0.2 to $0.4 \mathrm{~m}$ when the track ground contact length considered to keep in constant at $2.0 \mathrm{~m}$. Whereas, Fig. 6b shows that the vehicle motion resistance coefficient of the vehicle decreased $21.09 \%$ for 13.73 $\mathrm{kN}$ vehicle, $24.07 \%$ for $17.65 \mathrm{kN}$ vehicle and $24.5 \%$ for $21.58 \mathrm{kN}$ vehicle with increasing the track ground contact length from 1.3 to $2.2 \mathrm{~m}$ when the track width considered to keep in constant at $0.3 \mathrm{~m}$. From the justification of vehicle motion resistance coefficient based on vehicle track width and track ground contact

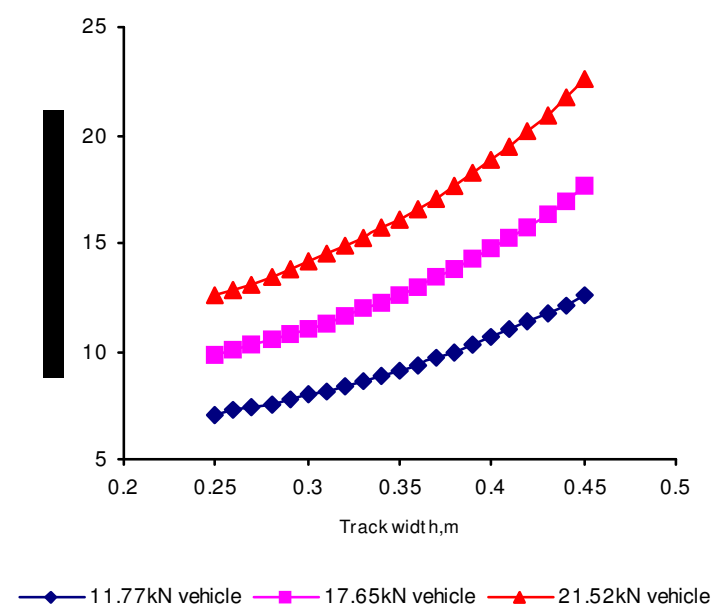

(a)

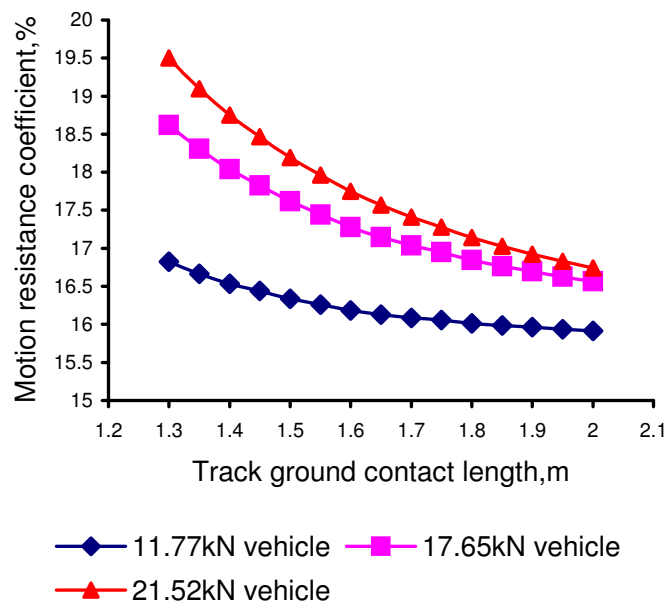

(b)

Fig. 6:Effect of Track Size on Vehicle Tractive Performance (a) Track Width and (b) Track Ground Contact Length

length, it could be noted that the vehicle track ground contact length should be considered to increase instead of increase the track width in order to get the vehicle lower ground contact pressure of $16 \mathrm{kN} \mathrm{m}^{-2}$ on Sepang peat terrain. Therefore, it was found that for a given overall dimension of $300 \times 2000 \mathrm{~mm}^{2}$ track system, the maximum motion resistance coefficient of the $19.62 \mathrm{kN}$ vehicle is $5.4 \%$, which could be good enough for a track vehicle on soft terrain [3].

Based on Fig. 4-6, it could be pointed out that if the $19.62 \mathrm{kN}$ vehicle track size is considered to be $300 \times 2000 \mathrm{~mm}^{2}$, the vehicle ground pressure exit on track-terrain interfaces is $16 \mathrm{kN} \mathrm{m}^{-2}$ with sinkage of 90 $\mathrm{mm}$ and motion resistance coefficient of $5.4 \%$. Therefore, the $19.62 \mathrm{kN}$ vehicle track system overall dimension can be optimised by selecting track width of $300 \mathrm{~mm}$ and ground contact length of $2000 \mathrm{~mm}$.

Track Grouser Size: To fully utilize the shear strength of the peat surface mat for generating tractive effort, the use of grouser on tracks would be required. From the field experiment on Sepang, it was found that the shear

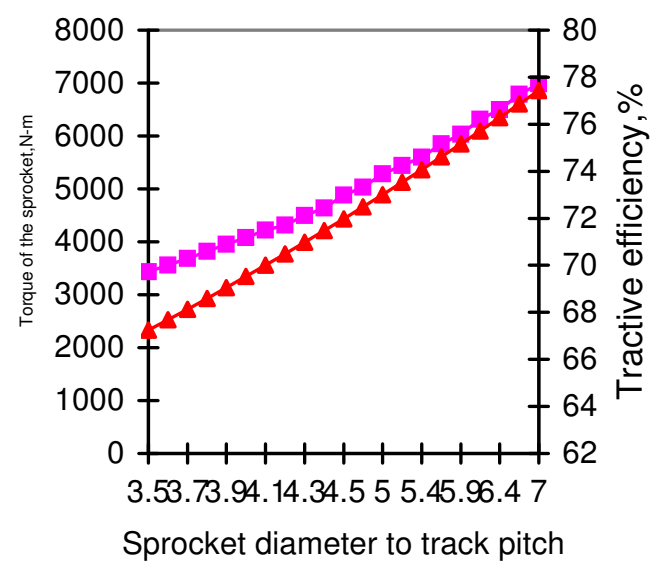

$\longrightarrow$ Sprocket torque, $\mathrm{N}-\mathrm{m} \longrightarrow$ Tractive efficiency,\%

Fig. 7: Variation of Tractive Efficiency and Sprocket Torque with Sprocket Diameter

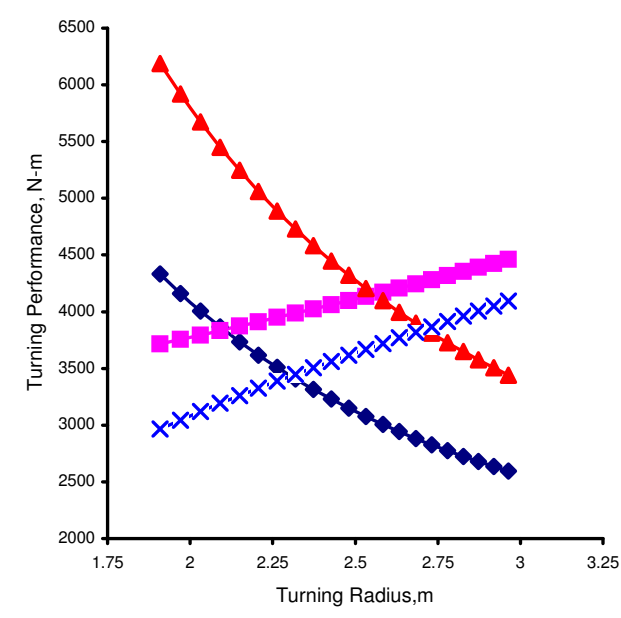

$\longrightarrow$ Sprocket Torque, $6 \mathrm{~km} / \mathrm{hr} \longrightarrow$ Turning moment, $10 \mathrm{~km} / \mathrm{hr}$

Fig. 8: Variation of Sprocket Torque and Turning Moment with Turning Radius 


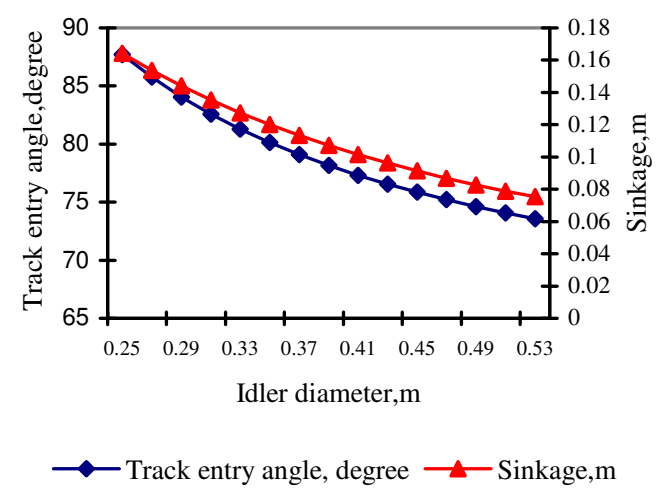

Fig. 9: Relationship Between Track Entry Angle, Sinkage and Idler Diameter

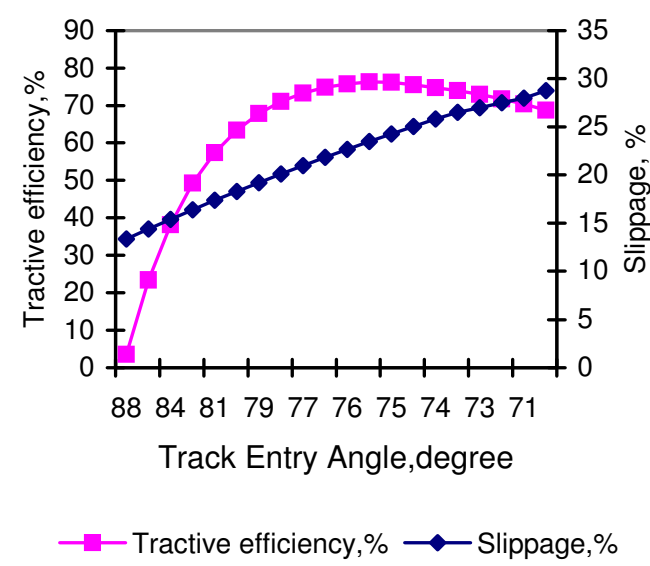

Fig. 10: Track Entry Angle, Tractive Performance and Slippage

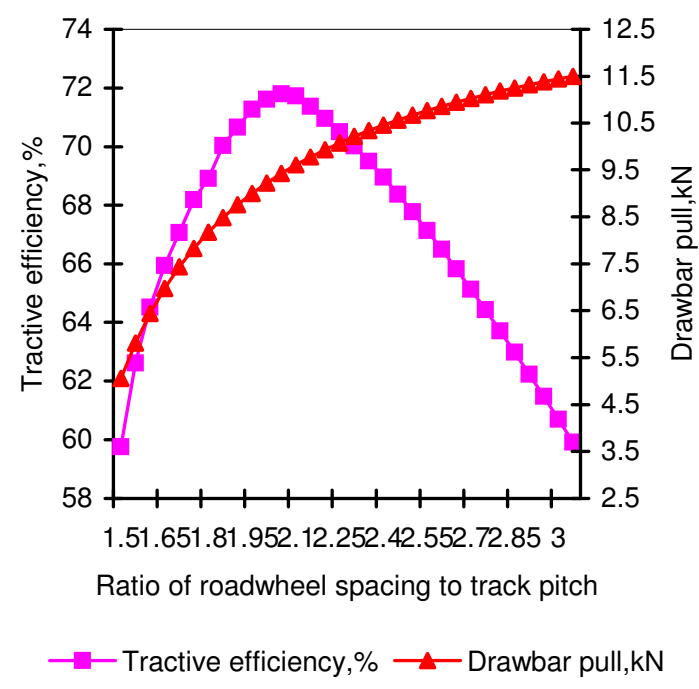

Fig. 11: Relationship Between Tractive Efficiency, Drawbar Pull and the Ratio of the Road-wheel Spacing to Track Pitch

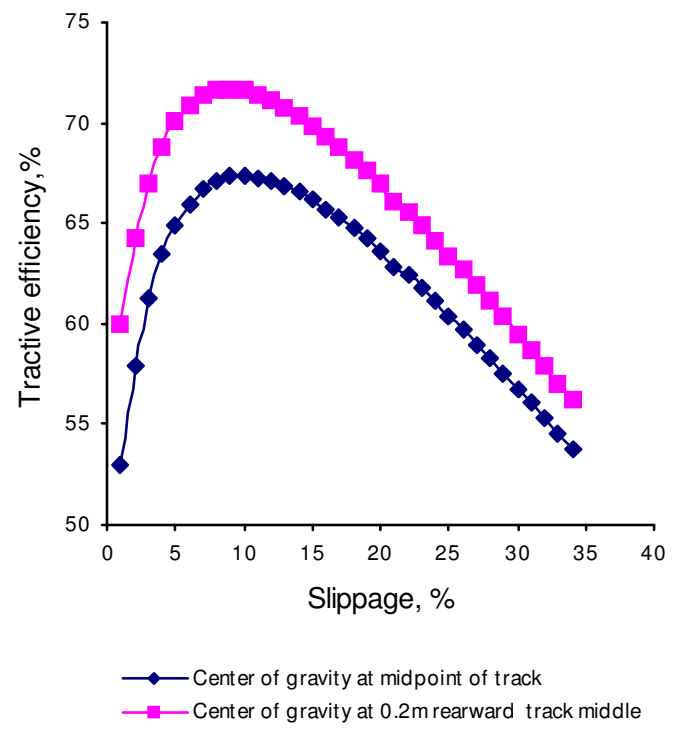

Fig. 12: Relationship Between Tractive Efficiency and Slippage

strength of the peat surface mat is considerably higher than that of the underlying peat deposit and that there is well defined shear-off point beyond which the resistance to shearing is significantly reduced. This would, however, considerably increase the risk of tearing off the surface mat unless the slip of the track is properly controlled. Thus, the use of aggressive grouser on vehicles for use in organic terrain does not appear to be desirable from traction as well as environmental viewpoints. The surface mat thickness of Sepang peat terrain was found to be about $0.1 \mathrm{~m}$. In order to fully utilize the shear strength of the surface mat and to increase the trafficability of the terrain the grouser height of the track is considered to be $0.06 \mathrm{~m}$.

Sprocket Location and Size: The location of drive sprocket has a noticeable effect on the vehicle tractive performance. Wong et al. (1986) reported that in forward motion, the top run of the track is subjected to higher tension when the sprocket is located at the front than when the sprocket is located at the rear. Thus, with a front sprocket drive, a larger proportion of the track is subjected to higher tension and the overall elongation and internal losses of the track will be higher than with a rear sprocket drive. With higher elongation, more track length is available for deflection and the track segments between road-wheels take fewer loads and the vibration of the track increase, which will cause the fluctuation of the track. Consequently, the sinkage and motion resistance will be higher and the mobility of the vehicle will be affected severely on the unprepared peat terrain. Therefore, the sprocket could be considered to locate at the rear part of the track system configuration 
in order to distribute the vehicle normal pressure to the track-terrain interfaces uniformly. The center point of the sprocket is considered the $(0,0)$ coordinate system of the vehicle.

Generally, it could be mentioned that the sprocket is the most important component of the vehicle track system, which propels the vehicle with sufficient torque, control the vehicle speed fluctuation and maintain the vehicle tractive performance. Therefore, the size of the sprocket can be determined from the relationship between the relationship between the sprocket torque, vehicle speed fluctuation and vehicle turning radius. From the simulation result, it was found that the ratio of the sprocket diameter to track pitch have significant effect on the vehicle tractive performance. Therefore, the ratio of the sprocket pitch diameter to track pitch should be a value which will stand to meet the field requirement.

Figure 7 shows that the torque of the sprocket decreases and turning moment resistance increases with increasing the turning radius of the vehicle. It could be mentioned that the vehicle developing torque of the vehicle must be higher than the turning moment resistance of the vehicle in order to maintain the steady state turn of the vehicle during turning at moderate speed of 6 to $10 \mathrm{~km} \mathrm{~h}^{-1}$. Figure 8 shows that the vehicle only can able to develop the sufficient torque to overcome the turning moment resistance if the vehicle turning radius is within the ranged of 3 to $3.5 \mathrm{~m}$. But, if the vehicle turning radius is considered to more than 3.3 $\mathrm{m}$ vehicle cannot maintain its steady state turn. Therefore, the vehicle turning radius is better to select $3.2 \mathrm{~m}$. Furthermore, if the vehicle turning radius is less than $3.2 \mathrm{~m}$, the vehicle have needed to develop higher torque cause to select higher hydraulic motor for the vehicle which might increase the initial cost and dry weight of the vehicle.

Figure 7 reveals that if the optimize turning radius of the vehicle was limited to $3.2 \mathrm{~m}$ the corresponding torque and turning moment were found 4900 and 3800 $\mathrm{Nm}$, respectively when the traveling speed of the vehicle was considered to $10 \mathrm{~km} \mathrm{~h}^{-1}$. For the same vehicle at same turning radius $3.2 \mathrm{~m}$ the corresponding torque and turning moment were found 3500 and 3200 $\mathrm{Nm}$, respectively, when the vehicle turning speed was considered to $6 \mathrm{~km} \mathrm{~h}^{-1}$. When this conclusion was drawn for the Fig. 8, it was found that the ratio of the vehicle sprocket pitch diameter to track pitch 4.00 corresponding to the maximum torque of the sprocket $4900 \mathrm{Nm}$. Furthermore, if the ratio of the sprocket pitch diameter to track pitch is 4.00 the corresponding tractive efficiency of the vehicle was found $71.25 \%$.

Further support to optimize the sprocket size of the vehicle track system, the following equation on vehicle speed fluctuation can be considered. For the relation of vehicle speed fluctuation and the ratio of the vehicle sprocket pitch diameter to tract pitch the following mathematical model of Wong [3] can be used:

$$
\delta=1-\sqrt{\left[1-\left(\frac{1}{\frac{D_{p r s}}{T_{p}}}\right)^{2}\right]}
$$

Where, $\delta$ is the speed fluctuation in percentage, $\mathrm{D}_{\mathrm{prs}} / \mathrm{T}_{\mathrm{p}}$ is the sprocket pitch diameter to track pitch in proportion.

Using $\mathrm{D}_{\text {prs }} / \mathrm{T}_{\mathrm{p}}$ equals to 4.00 , the computed value of $\delta$ is $3.17 \%$. According to Wong [3], the industrial and agricultural track vehicle speed fluctuation should be in the range of 3.72 to $2.75 \%$. Since the speed fluctuation of the vehicle was found of $3.17 \%$, the ratio of the vehicle sprocket pitch diameter to track pitch can be optimized at 4.00. Consequently, the sprocket pitch diameter was optimized at $400 \mathrm{~mm}$ by using the track pitch of $100 \mathrm{~mm}$.

Idler Location and Size: Idler is located at $-2.0 \mathrm{~m}$ front of the track system. It was earlier reported that the surface mat thickness of Sepang peat terrain in the ranged of 100 to $250 \mathrm{~mm}$ which is considered the supporting platform of the vehicle. It could be noted that if the sinkage of any vehicle on the Sepang peat terrain is more than $100 \mathrm{~mm}$ will cause the vehicle to bog down. Furthermore, from the simulation it was found that the track entry angle was significantly affect the vehicle front idler size and tractive performance. Therefore, from the relationship between the vehicle sinkage, track entry angle and idler diameter, the idler diameter can be identified. Figure 9 shows that the vehicle track entry angle at front idler and sinkage decreases with increasing vehicle front idler diameter. If the vehicle critical sinkage of the vehicle is considered to $100 \mathrm{~mm}$, the corresponding front idler diameter and track entry angle were found $400 \mathrm{~mm}$ and $78^{\circ}$, respectively.

This conclusion can be further supported from the relationship between the track entry angle, slippage and vehicle tractive performance. Figure 10 shows that the relationship between the vehicle track entry angle, slippage and tractive efficiency. At track entry angle $78^{\circ}$, the vehicle slippage and tractive efficiency were found $18 \%$ and $70.5 \%$, respectively, which was found at sprocket pitch diameter of $400 \mathrm{~mm}$. Therefore, the front idler diameter $400 \mathrm{~mm}$ can be optimized at 400 $\mathrm{mm}$ for getting the tractive efficiency of the vehicle $70.5 \%$ and high productivity.

Roadwheel Diameter, Track Pitch and Number of Roadwheel: Wong [3] reported that the ratio of road wheel spacing to track pitch is a significant parameter that affects the tractive performance of tracked vehicle, particularly on soft terrain. The decrease in the track motion resistance coefficient with the increase of the 
number of road wheels was primarily due to the reduction in the peak pressures and sinkage under the road wheels. The longer track pitch would lead to an improvement in tractive performance over soft terrain. But, it may cause a wider fluctuation in vehicle speed and higher associated vibration.

Consequently, a proper compromise between tractive performance and smoothness of operation must be struck. Road-wheel diameter can be predicted based on the following equation:

$$
S_{r}=\frac{D_{1}}{2}+\frac{D_{2}}{2}+G
$$

Where, $S_{r}$ is the road-wheel spacing in $m m, D_{1}$ is the first road-wheel diameter in $\mathrm{mm}, \mathrm{D}_{2}$ is the second roadwheel diameter in $\mathrm{mm}$ and $\mathrm{G}$ is the gap between consecutive road-wheel is assumed to be $5 \mathrm{~mm}$ for avoiding the track deflection between the consecutive road-wheel.

In the track system all the road-wheel dimension $\left(D_{1}=D_{2}=------=D_{7}\right)$ are considered as equal size. If the roadwheel spacing equals to $225 \mathrm{~mm}$, the gap between two consecutive road-wheel on the track system equals to $5 \mathrm{~mm}$, the computed value of road-wheel diameter equals to $220 \mathrm{~mm}$.

Table 4: Analysis Drawbar Pull Variation

\begin{tabular}{lllll}
\hline Mean & SD & SE & T & Prob $>|\mathrm{T}|$ \\
0.7298710 & 0.6197657 & 0.1421840 & 5.1332850 & 0.0001 \\
\hline
\end{tabular}

Table 5: Analysis Tractive Efficiency Variation

\begin{tabular}{lllll}
\hline Mean & SD & SE & T & Prob $>|\mathrm{T}|$ \\
1.7698045 & 2.3788241 & 0.5457397 & 3.2429464 & 0.0045 \\
\hline
\end{tabular}

Table 6: Basic Design Parameters of the Special Segmented Rubber Tracked Vehicle

\begin{tabular}{|c|c|c|}
\hline \multicolumn{3}{|l|}{ Vehicle Parameters } \\
\hline Total weight including $9.81 \mathrm{kN}$ payload, $\mathrm{kN}$ & $\mathrm{W}$ & 19.62 \\
\hline Vehicle traveling speed, $\mathrm{km} \mathrm{h}^{-1}$ & $v_{t}$ & 10 \\
\hline Center of gravity, $\mathrm{x}$ coordinate, $\mathrm{m}$ & $\mathrm{x}_{\mathrm{cg}}$ & -0.80 \\
\hline Centre of gravity, $y$ coordinate, $m$ & $\mathrm{y}_{\mathrm{cg}}$ & 0.45 \\
\hline Sprocket pitch diameter, m & $\mathrm{D}_{\mathrm{rs}}$ & 0.40 \\
\hline Idler diameter, $\mathrm{m}$ & $\mathrm{D}_{\mathrm{fi}}$ & 0.40 \\
\hline Idler center, $\mathrm{x}$ coordinate, $\mathrm{m}$ & $\mathrm{x}_{\mathrm{cfi}}$ & -2.0 \\
\hline Idler center, y coordinate, $\mathrm{m}$ & $\mathrm{y}_{\mathrm{cfi}}$ & 0 \\
\hline Number of road-wheels (each side) & $\mathrm{n}$ & 7 \\
\hline Road-wheel diameter, $\mathrm{m}$ & $D_{\mathrm{r}}$ & 0.22 \\
\hline Road-wheel spacing, $\mathrm{m}$ & $\mathrm{S}_{\mathrm{r}}$ & 0.225 \\
\hline Number of supporting rollers (each side) & $\mathrm{n}_{\mathrm{s}}$ & 3 \\
\hline Supporting rollers diameter, $\mathrm{m}$ & $D_{\mathrm{s}}$ & 0.20 \\
\hline \multicolumn{3}{|l|}{ Track Parameters } \\
\hline Track total length (each side), $\mathrm{m}$ & $\mathrm{L}_{\mathrm{c}}$ & 5.90 \\
\hline Track pitch, m & $\mathrm{T}_{\mathrm{p}}$ & 0.10 \\
\hline Track width, $\mathrm{m}$ & $\mathrm{B}$ & 0.30 \\
\hline Track ground contact length, $\mathrm{m}$ & $\mathrm{L}$ & 2.00 \\
\hline Road-wheel spacing to track pitch & $\mathrm{S}_{\mathrm{r}} / \mathrm{T}_{\mathrm{p}}$ & 2.25 \\
\hline Vehicle speed fluctuation, percentage & $\delta$ & 3.17 \\
\hline Grouser height, $\mathrm{m}$ & $\mathrm{H}$ & 0.06 \\
\hline
\end{tabular}

Note: Coordinates origin is at the center of the sprocket. Positive $\mathrm{x}$ and y coordinates are to the rear and top, respectively.
Figure 11 shows that the vehicle drawbar pull increases with increasing the ratio road-wheel spacing to track pitch and tractive efficiency increases with increasing the ratio of road-wheel spacing to track pitch until 2.1 and then decreases with further increasing of the ratio of road-wheel spacing to track pitch. If the ratio of road-wheel spacing to track pitch is considered to be 2.25, the tractive efficiency of the vehicle is found $70.5 \%$. Whereas, the tractive efficiency of the vehicle is found $70.5 \%$ for the optimum sprocket pitch diameter of $400 \mathrm{~mm}$ and idler diameters of $400 \mathrm{~mm}$. Therefore, the ratio of road-wheel spacing to track pitch should be 2.25 if the optimum sprocket pitch diameter and idler diameters each is limited to $400 \mathrm{~mm}$. By using $\mathrm{S}_{\mathrm{r}} / \mathrm{T}_{\mathrm{p}}$ equals to 2.25 and $S_{r}$ equals to $225 \mathrm{~mm}$, the computed value of $\mathrm{T}_{\mathrm{p}}$ equals to $100 \mathrm{~mm}$.

The number of road-wheels can be computed based on Fig. 1 by the following equation:

$\mathrm{n}_{\mathrm{r}}=\frac{\left(\mathrm{L}-\left(\frac{\mathrm{D}_{\mathrm{rs}}+\mathrm{D}_{\mathrm{fi}}}{2}\right)\right)}{\left(\mathrm{D}_{\mathrm{r}}+\mathrm{G}\right)}$

Where, $\mathrm{L}$ is the total ground contact length in $\mathrm{mm}, \mathrm{D}_{\mathrm{rs}}$ is the outside diameter of the sprocket in $\mathrm{mm}, \mathrm{D}_{\mathrm{fi}}$ and $\mathrm{D}_{\mathrm{r}}$ are the diameter of the front idler and road-wheel in $\mathrm{mm}$ and $\mathrm{n}_{\mathrm{r}}$ is the number of road-wheel. The outside diameter of the sprocket (i.e, $D_{r s}=D_{p r s}+H / 2$ ) is considered to $460 \mathrm{~mm}$ based on the grouser height.

By using L equals to $2000 \mathrm{~mm}, \mathrm{D}_{\mathrm{rs}}$ equals to $400 \mathrm{~mm}$, $\mathrm{D}_{\mathrm{fi}}$ equals to $400 \mathrm{~mm}, \mathrm{D}_{\mathrm{r}}$ equals to $220 \mathrm{~mm}, \mathrm{G}$ equals to $5 \mathrm{~mm}$, the computed value of $\mathrm{n}_{\mathrm{r}}$ is 7 . Therefore, total number of road-wheel seven with diameter of $220 \mathrm{~mm}$ on the $19.62 \mathrm{kN}$ vehicle track system would significantly reduce vehicle vibration during traversing on the unprepared peat terrain by making zero deflection of the track between two consecutive roadwheel.

Center of Gravity Location: Center of gravity of a tracked vehicle is a most important design parameter for getting the high tractive performance. Figure 12 shows that the tractive efficiency of the vehicle increases steeply with increasing the slippage of the vehicle until a certain value and then start to decrease with increasing the slippage of the vehicle. The vehicle under consideration with total weight $19.62 \mathrm{kN}$ including payload of $5.89 \mathrm{kN}$ is traversing on a zero slope terrain with traveling speed of $10 \mathrm{~km} \mathrm{~h}^{-1}$. Figure 12 shows the maximum tractive efficiency of $79.8 \%$ at $11 \%$ slippage for the vehicle with center of gravity located at $300 \mathrm{~mm}$ rearward from the mid-point of the track ground contact length and $70.5 \%$ at $12 \%$ slippage for the vehicle with center of gravity located at the midpoint of the track ground contact length. 
From the comparison of the vehicle based on the location of center of gravity, it is found that the tractive efficiency of the vehicle with center of gravity is located at $200 \mathrm{~mm}$ rearward from the mid point of the track ground contact length is $13.2 \%$ higher than the tractive efficiency of the vehicle with the center of gravity is located at the mid-point of the track ground contact length. The variation of tractive efficiency is found between the vehicle with the locations of center of gravity due to the difference of external motion resistance. It could be pointed out that the vehicle with location of center of gravity at $200 \mathrm{~mm}$ rearward from the mid point of the track ground contact length reveals lower sinkage at the frontal part of the track ground contact part causes the lower external motion resistance and the vehicle consume lower engine power for developing effective tractive effort in order to traverse the vehicle easily on the low bearing capacity peat terrain. Whereas, the vehicle with location of center of gravity at the midpoint of the track ground contact length reveals the equal sinkage to all over the ground contact part causes the higher external motion resistance and vehicle consume maximum engine power for developing the required tractive effort in order to traverse the vehicle on the low bearing capacity peat terrain. Therefore, the vehicle center of gravity location of $300 \mathrm{~mm}$ rearward from the mid-point of the track ground contact length could be optimized the center of gravity location for the vehicle.

The basic design parameters of the vehicle found from the simulation study are shown in Table 6 .

Vehicle Simulated Performance: The vehicle tractive performance including vehicle external motion

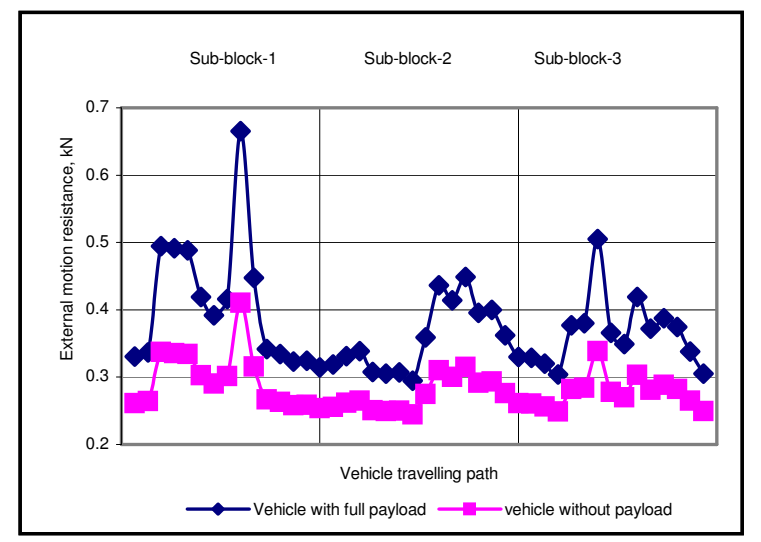

(a)

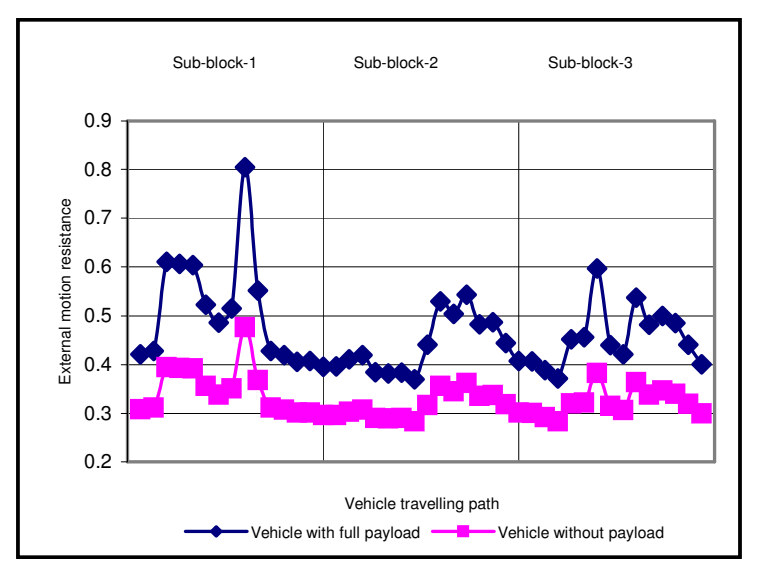

(b)

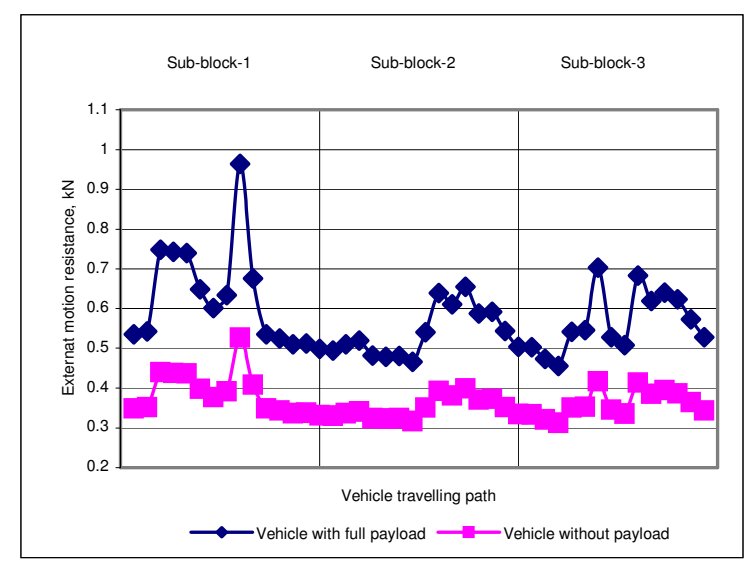

(c)

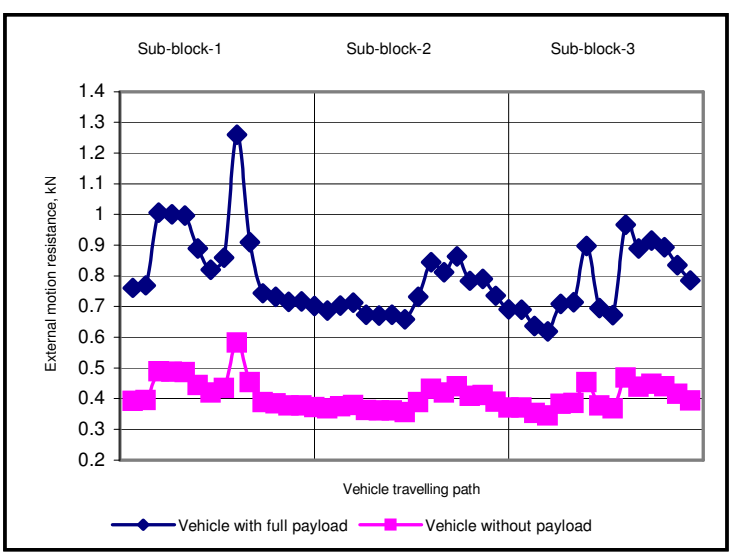

(d)

Fig. 13: Effect of Vehicle Slip on Vehicle External Motion Resistance (a) Slip of 5\% , (b) Slip of $10 \%$, (c) Slip of $15 \%$ and (d) Slip of $20 \%$ 


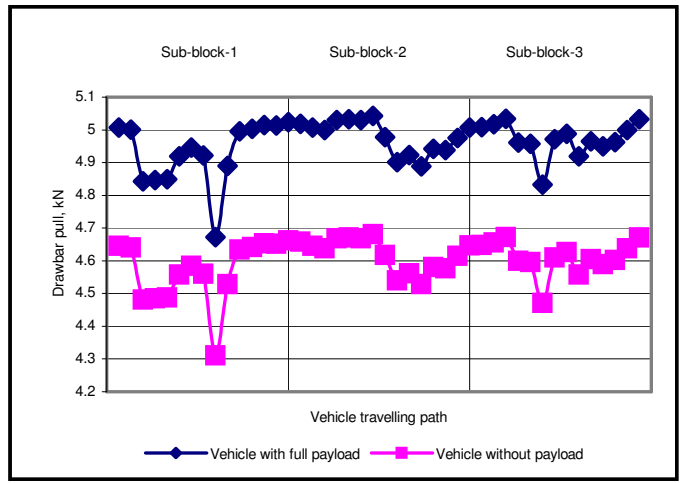

(a)

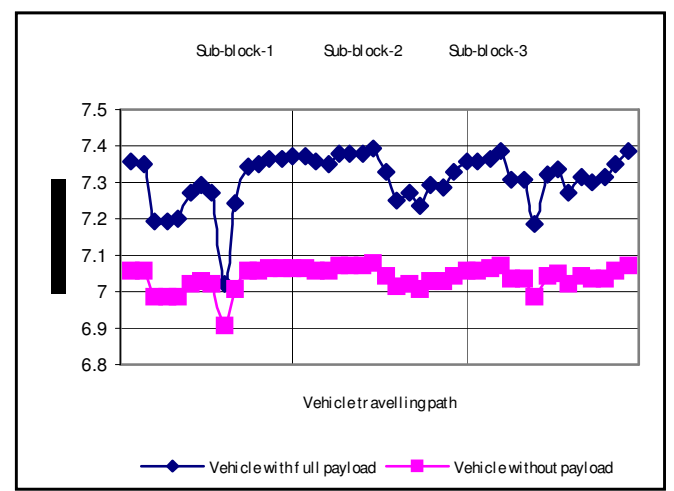

(b)

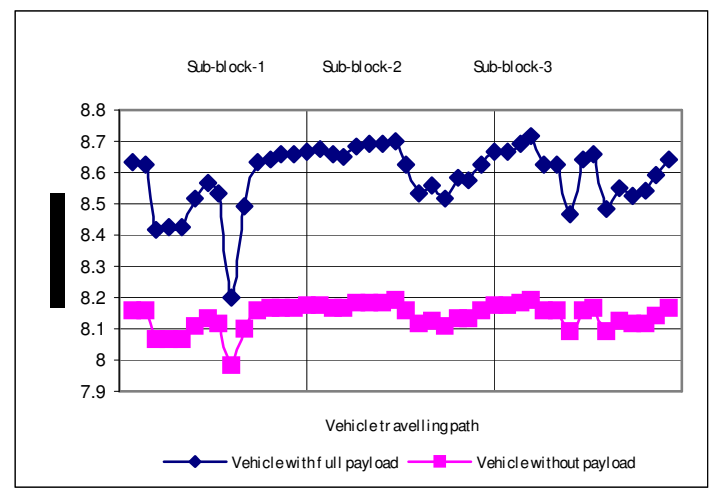

(c)

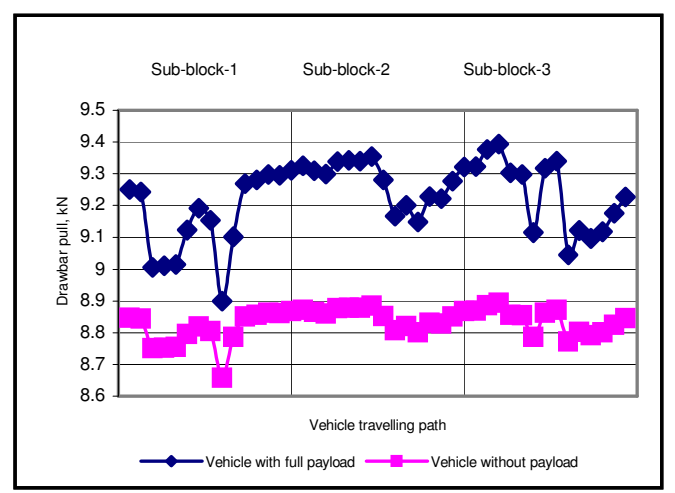

(d)

Fig. 14: Effect of Vehicle Slip on Vehicle Drawbar Pull (a) Slip of 5\%, (b) Slip of 10\%, (c) Slip of $15 \%$, and (d) Slip of $20 \%$

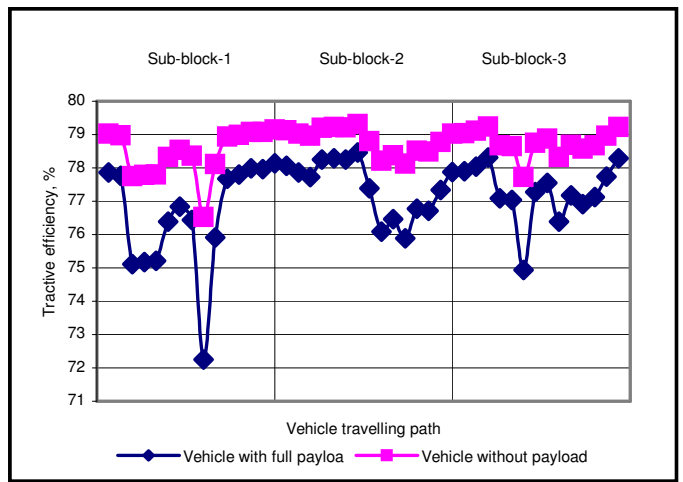

(a)

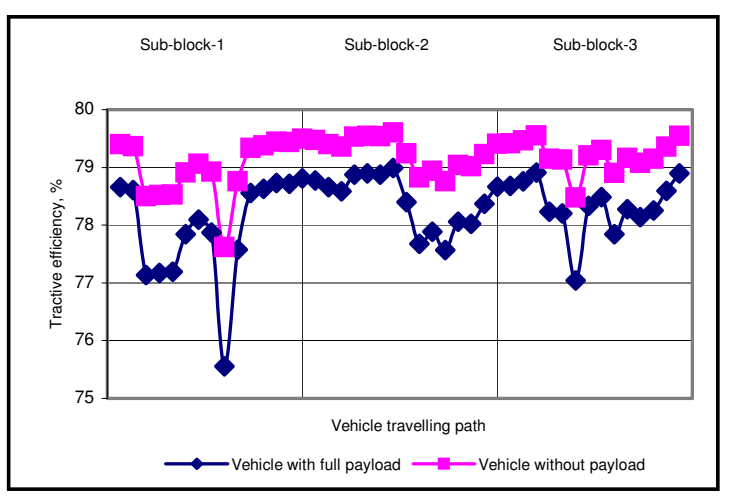

(b)

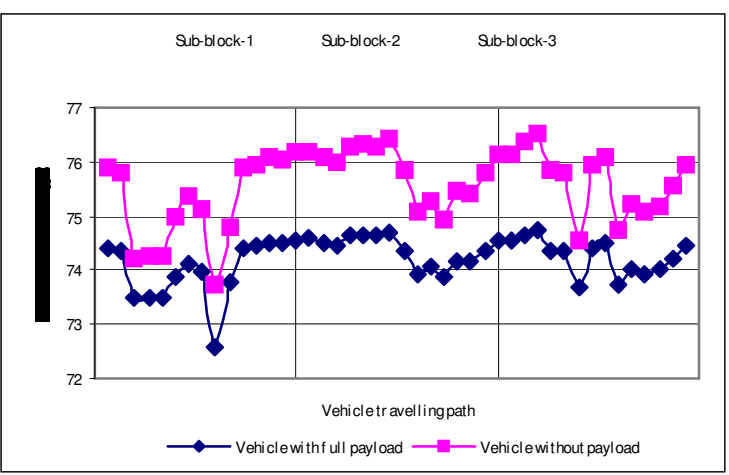

(c)

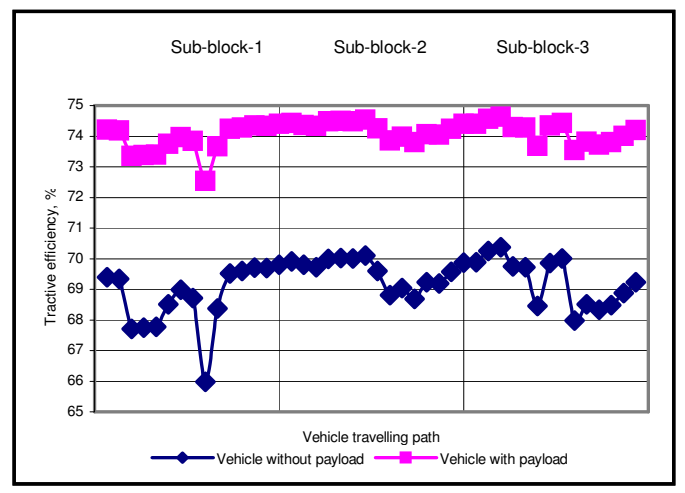

(d)

Fig. 15: Effect of Vehicle Slip on Vehicle Tractive Efficiency (a) Slip of 5\%, (b) Slip of 10\%, (c) Slip of $15 \%$ and (d) Slip of $20 \%$ 
resistance due to soil compaction and bull dozing effect, drawbar pull and tractive efficiency was simulated by using the Sepang peat terrain parameters such as terrain bulk density (dry base) $\gamma$, internal frictional angle $\varphi$, cohesiveness $c$, shear deformation modulus $\mathrm{K}$, peat surface mat stiffness $\mathrm{m}_{\mathrm{m}}$ and underlying peat stiffness $\mathrm{k}_{\mathrm{p}}$. The sepang peat terrain parameters were workedout by Ataur et al. [2]. For the given terrain condition, we analyzed the simulated results to evaluate the effect of vehicle slips on vehicle performance parameters such as vehicle external motion resistance, drawbar pull and tractive efficiency for each of the sub-blocks. Simulated results show that the slip of the vehicle does not affect much on the vehicle performance when the vehicle traverses on peat terrain without payload. Whereas, it affects on the vehicle performance significantly when the vehicle traverses on peat terrain with full payload. Therefore, the following vehicle performance analysis were made based on the vehicle with full payload. For the simulation of the vehicle performance, the slippage of the vehicle was varied from 5 to $20 \%$.

Effect of Vehicle Slip on Vehicle External Motion Resistance: The total external motion resistance $\mathrm{R}_{\mathrm{etm}}$ is the whole of the forces being opposed to the movement of a vehicle. The external motion resistances result from the interaction of the tracks and the environment, such as the slope of the terrain or its state. The objective of the motion resistance tests is to measure $\mathrm{R}_{\mathrm{T}}$ and then to determine $R_{i}$ and $R_{e t m}$. The sum of resistance $R_{T}$ is the force necessary to develop the vehicle in order to traverse on the low bearing capacity peat terrain. If any vehicle fails to do so, the vehicle cannot traverse on the terrain to perform its task. Figure 13 shows the effect of slippage on vehicle external motion resistance. The result shows that the external motion resistance of the vehicle increases with increasing the slippage of the vehicle. The computed internal motion resistance of the vehicle equals to $0.75 \mathrm{kN}$ and added with the maximum external motion resistance of the vehicle, the total motion resistance of the vehicle was found 7.23, 7.9, 8.67 and $10.19 \%$ of the total weight of the vehicle for the slippage of 5, 10, 15 and 20\%, respectively.

Based on Wong [3], the total motion resistance for the vehicle of rigid link track on soft terrain should be in the range of 6 to $9 \%$ of the vehicle total weight. From the simulation result on the proposed vehicle at $20 \%$ slippage, it is found that the total motion resistance of the vehicle is $13.2 \%$ higher than the recommended total motion resistance of the vehicle. While, the total motion resistance of the vehicle at slippage of 5, 10 and 15\% are lower than the total motion resistance of the vehicle. Based on the simulation result of the vehicles total motion resistance it could be concluded that if the vehicle traverse on peat terrain with full payload at slippage of $20 \%$, the vehicle will be in trouble.
Therefore, to avoid the risk of the vehicle bog down in the field during traversing for getting the high performance, the vehicle slippage should be control in the ranged to 5 to $15 \%$.

Effect of Vehicle Slip on Vehicle Drawbar Pull: The objective of the drawbar pull tests is to obtain $D_{P}$ for the vehicle on the terrain. The principle is to measure the necessary force that must be provided by the vehicle to carry the dead load that considered as the payload of the vehicle. The speeds of the vehicle and vehicle tracks are used to calculate the slip i between the tracks and the soil.

From the overall comparison of the vehicle drawbar pull between the vehicle with full payload and without payload based on Fig. 14, it was found that the vehicle with full payload shows the higher drawbar pull than the vehicle without payload. Therefore, the ballast change of the vehicle drawbar pull could be achieved by adding the payload. This is happened because of vehicle maximum tractive effort development to overcome the maximum external motion resistance. But, it is very much limited by the strength of the low bearing capacity peat terrain and the vehicle engine power.

The result shows that the drawbar pull of the vehicle increases with increasing the slippage of the vehicle. This is because of vehicle engine power consumption for developing the tractive effort to overcome the motion resistance. So, once the consumption of vehicle engine power reached to the maximum limit of vehicle engine power the vehicle will not be able to develop the additional tractive effort even increasing the slippage and motion resistance. In that case, the vehicle drawbar pull will be constant and once this will be start to sharply drop due the increasing of motion resistance for slippage.

Effect of Vehicle Slip on Vehicle Tractive Efficiency: Figure 15 shows the effect of the slippage of vehicle on vehicles tractive efficiency when the vehicle travels on different sub-block. From the comparison of the vehicle tractive efficiency between the vehicle with full payload and without payload, it is found that the vehicle without full payload shows the higher tractive efficiency than the vehicle with full payload. Based on the comparison result of vehicles drawbar pull, it could be concluded based on the definition of tractive efficiency that the vehicle with full payload should be higher tractive efficiency than the vehicle without payload. But, the vehicle with full payload showed the lower tractive efficiency (by the definition tractive efficiency is the ratio of drawbar pull to engine power) than the vehicle without payload. Because the vehicle with full payload was consumed higher engine power than the vehicle without payload in order to traverse forward with overcoming motion resistance which was 
found from the simulation result and also could be from the field experiment.

In this simulation, the maximum sinkage of the vehicle on the respective sub-block was considered the worst condition of the Sepang peat terrain. Based on the worst condition, the vehicle tractive efficiency increases with increasing the slippage of the vehicle in a certain value then it decreases with increasing the slippage of the vehicle. For example, the vehicle in sub-block 1 provided the tractive efficiency of $72.2 \%$ for slippage of $5 \%, 75.5 \%$ for the slippage of $10 \%, 72.5 \%$ for the slippage of $15 \%$ and $65.98 \%$ for the slippage of $20 \%$. If the simulation results for the other sub-block are analyzed in the same way, the same results were appeared. Therefore, the maximum tractive efficiency of the vehicle on the worst condition of the peat terrain appeared at $10 \%$ slippage.

\section{CONCLUSION}

Based on the results of detailed study on vehicle parameters, an optimized track system configuration for the $19.62 \mathrm{kN}$ vehicle has seven roadwheels with diameter of $0.24 \mathrm{~m}$, a track pitch of $0.1 \mathrm{~m}$, a ratio of the initial track tension to vehicle weight of $12 \%$, a location of center of gravity at $30 \mathrm{~cm}$ ahead of the mid-point of the track ground contact length ensure the vehicle to develop tractive performance of $73 \%$ during traversing at $10 \mathrm{~km} \mathrm{~h}^{-1}$ on the specified peat terrain.

Based on the location of center of gravity of the vehicle it is found that the tractive performance is $11.75 \%$ higher for the $19.62 \mathrm{kN}$ vehicle when its center of gravity is located at $30 \mathrm{~cm}$ ahead the mid point of the track system.

The new developing mathematical model and analystical simulation method will be a useful tool for design engineers to design off-road vehicles on unprepared peat terrain.

Based on the simulation result analysis, it is found that the slippage of the vehicle affect the vehicle overall performance significantly. In order to maintain the vehicle in normal operation conditions, i.e, with satisfactory performance, vehicle slippage and sinkage should be kept within the slip sinkage range of 0 to $15 \%$ and sinkage range of 0 to $100 \mathrm{~mm}$.

The simulated performance results such as vehicle average motion resistance coefficient (the ratio total motion resistance to total vehicle weight) of 6.8 to $7.9 \%$, drawbar pull coefficient (the ratio of drawbar pull to total vehicle weight) of 25.22 to $47 \%$ and the tractive efficiency of 74 to $77 \%$ for the vehicle slippage of 5 to $20 \%$ represents that the vehicle can meet the peat terrain field requirement using its total power consumption at the optimum.

\section{ACKNOWLEDGEMENT}

This research project is classified under RM7 IRPA Project No. 01-02-04-0135. The authors are very grateful to the Ministry of Science, Technology and The Environment of Malaysia for granting the fund for this research project.

\section{Notations}

$\theta_{\mathrm{fi}} \quad=$ Track entry angle at front idler, ${ }^{\circ}$

$\mathrm{j}_{\mathrm{x}} \quad=$ Shear dispalcement for track small part, $\mathrm{m}$

$\theta_{\mathrm{ti}} \quad=$ Track trim angle, ${ }^{\circ}$

$\mathrm{K}_{\mathrm{w}} \quad=$ Shear deformation modulus, $\mathrm{m}$

$\theta_{\mathrm{rs}} \quad=$ Track exit angle at rear sprocket, ${ }^{\circ}$

$\mathrm{K}_{\mathrm{wfi}}=$ Shear deformation modulus for front idler, $\mathrm{m}$

$\varphi \quad=$ Peat internal frictional angle, ${ }^{\circ}$

$\mathrm{K}_{\mathrm{wrs}}=$ Shear deformation modulus for rear sprocket, $\mathrm{m}$

$\alpha \quad=$ Grouser setting angle with track,

$\mathrm{K}_{\mathrm{wmp}}=$ Shear deformation modulus for track main part,m

$\beta_{\mathrm{rr}} \quad=$ Roadwheel rotational angle for max. shear strength, ${ }^{\circ}$

$\mathrm{k}_{\mathrm{p}} \quad=$ Underlying peat stiffness, $\mathrm{kN} \mathrm{m}^{-3}$

$\tau \quad=$ Peat terrain shearing stress, $\mathrm{kN} \mathrm{m}^{-2}$

$\mathrm{L} \quad=$ Length of the track ground main part, $\mathrm{m}$

$\sigma \quad=$ Vehicle normal stress, $\mathrm{kN} \mathrm{m}^{-2}$

$\mathrm{L}_{\mathrm{fib}} \quad=$ Length of the front idler bottom track part, $\mathrm{m}$

$\gamma_{\mathrm{d}} \quad=$ Peat bulk density (dry basis), $\mathrm{kN} \mathrm{m}^{-3}$

$\mathrm{L}_{\mathrm{rsb}} \quad=$ Length of the rear sprocket bottom track part,m

$\omega=$ Moisture content, $\%$

$\mathrm{m} \quad=$ Peat surface mat stiffness, $\mathrm{kN} \mathrm{m}^{-3}$

$\delta \quad=$ Track fluctuation, $\%$

$\mathrm{n} \quad=$ Number of road-wheel

$\mathrm{B} \quad=$ Track width, $\mathrm{m}$

$\mathrm{P}_{0} \quad=$ Reaction force at the track main part, $\mathrm{kN} \mathrm{m}^{-2}$

$\mathrm{C}=$ Peat terrain coghesiveness, $\mathrm{kN} \mathrm{m}^{-2}$

$\mathrm{P}_{\mathrm{fi}}=$ Reaction force at the idler track part, $\mathrm{kN} \mathrm{m}^{-2}$

C.G =Vehicle centre of gravity

$\mathrm{P}_{\mathrm{rs}} \quad=$ Reaction force at the sprocket track part, $\mathrm{kN} \mathrm{m}^{-2}$

$\mathrm{D}_{\mathrm{hfi}}=$ Peat terrain hydraulic diameter due to front idler,m

$\mathrm{Q} \quad=$ Torque of the sprockt, $\mathrm{kN}-\mathrm{m}$

$\mathrm{D}_{\mathrm{hmp}}=$ Peat terrain hydraulic diameter due to main partl,m

$\mathrm{R}_{\mathrm{c}} \quad=$ Motion resistance due to terrain compaction, $\mathrm{kN}$

$\mathrm{D}_{\text {hrs }}=$ Peat terrain hydraulic diameter due to rear sprocket, $\mathrm{m}$

$\mathrm{R}_{\mathrm{fic}}=$ Motion resist. for idler terrain compaction, $\mathrm{kN}$

$\mathrm{D}_{\mathrm{p}} \quad=$ Drawbar pull, $\mathrm{kN}$

$\mathrm{R}_{\mathrm{rsc}}=$ Motion resist. for sprocket terrain compaction, $\mathrm{kN}$ 
$\mathrm{D}_{\mathrm{r}} \quad=$ Roadwheel diameter, $\mathrm{m}$

$\mathrm{R}_{\mathrm{msc}}=$ Motion resist. for main part terrain compaction, $\mathrm{kN}$

$\mathrm{D}_{\mathrm{rs}} \quad=$ Rear sprocket diameter, $\mathrm{m}$

$\mathrm{R}_{\mathrm{b}} \quad=$ Motion resist. for bull dozing effect, $\mathrm{kN}$

$\mathrm{E} \quad=$ Distance of the track midle point to C.G,m

$\mathrm{R}_{\mathrm{fib}}=$ Motion resist. for front idler bull dozing effect, $\mathrm{kN}$

$\mathrm{E}^{1} \quad=$ Exponential

$\mathrm{R}_{\mathrm{rsb}}=$ Motion resist. for sprocket bull dozing effect, $\mathrm{kN}$

$\mathrm{F}_{\mathrm{b}} \quad=$ Vehicle tractive effort at track bottom part, $\mathrm{kN}$

$\mathrm{R}_{\mathrm{mpb}}=$ Motion resist. for main part bull dozing effect, $\mathrm{kN}$

$\mathrm{F}_{\mathrm{fib}} \quad=$ Vehicle tractive effort at idler bottom track part, $\mathrm{kN}$

$\mathrm{R}_{\mathrm{tm}}=$ Total external motion resistance, $\mathrm{kN}$

$\mathrm{F}_{\mathrm{rsb}} \quad=$ Vehicle tractive effort at sproket bottom track part, $\mathrm{kN}$

$\mathrm{R}_{\mathrm{fi}} \quad=$ Front idler radius, $\mathrm{m}$

$\mathrm{F}_{\mathrm{mb}} \quad=$ Vehicle tractive effort at main part bottom track part, $\mathrm{kN}$

$\mathrm{R}_{\mathrm{rs}} \quad=$ Rear sprocket radius, $\mathrm{m}$

$\mathrm{F}_{\mathrm{s}} \quad=$ Vehicle tractive effort at track side, $\mathrm{kN}$

$\mathrm{S}_{\mathrm{r}} \quad$ =Spacing between consecutive roadwheel,m

$\mathrm{F}_{\mathrm{fis}} \quad=$ Vehicle tractive effort at idler track side, $\mathrm{kN}$

$\mathrm{T}=$ Initial track tension, $\mathrm{kN}$

$\mathrm{F}_{\text {rss }} \quad=$ Vehicle tractive effort at sprocket track side, $\mathrm{kN}$

$\mathrm{T}_{\mathrm{p}} \quad=$ Track pitch, $\mathrm{m}$

$\mathrm{F}_{\mathrm{ms}} \quad=$ Vehicle tractive effort at main track track side, $\mathrm{kN}$

$\mathrm{V}_{\mathrm{t}} \quad=$ Vehicle theoritical speed, $\mathrm{km} \mathrm{h}^{-1}$

$\mathrm{F}_{\mathrm{tt}} \quad=$ Total tractive effort, $\mathrm{kN}$

$\mathrm{W}=$ Vehicle total weight including payload $5.88 \mathrm{kN}, \mathrm{kN}$

$\mathrm{H}=$ Grouser height, $\mathrm{m}$

$\mathrm{x} \quad=$ Track divisional distance, $\mathrm{m}$ $\mathrm{h}_{\mathrm{cg}} \quad=$ C.G height, $\mathrm{m}$

$\mathrm{z}_{\mathrm{c}} \quad=$ Vehicle critical sinkage, $\mathrm{m}$

I $=$ Vehicle slippage, $\%$

$\mathrm{z}_{\mathrm{fi}} \quad=$ Sinkage of the front idler,m

$\mathrm{i}_{\mathrm{fi}} \quad=$ Slippage of the front idler, $\%$

$\mathrm{z}_{\mathrm{rs}} \quad=$ Sinkage of the rear sprocket, $\mathrm{m}$

$\mathrm{i}_{\mathrm{rs}} \quad=$ Slippage of the rear sprocket, $\%$

$\mathrm{z}_{\mathrm{mp}} \quad=$ Sinkage of the track main part, $\mathrm{m}$

$i_{m p}=$ Slippage of the track main part, $\%$

$\mathrm{z}_{\mathrm{n}} \quad=$ Sinkage of the $\mathrm{n}$ number road-wheel, $\mathrm{m}$

\section{REFERENCES}

1. ASAE, Agricultural Engineers Yearbook of Standards, 1996. American Society of Agricultural Engineers, Michigan.

2. Ataur, R., Y. Azmi, M. Zohadie, A. Desa, I. Wan and A.F. Kheiralla, 2004. Mechanical properties in relation to vehicle mobility of Sepang peat terrain in Malaysia. J. Terramechanics, 41: 25-40.

3. Wong, J.Y., 1998. Optimization of design parameters of rigid-link track systems using an advanced computer aided method. Proc. Instn. Mech. Engrs, Part D, J. Automobile Eng., 212: 153-167.

4. Wong, J.Y., 2001. Theory of Ground Vehicle. $2^{\text {nd }}$ Edn. John Wiley and Sons Inc. New York.

5. Ooi, H.S., 1986. Performance of modified kubota carrier RC20P and Porter P6-121 on peat soil. MARDI Report No. 110. 